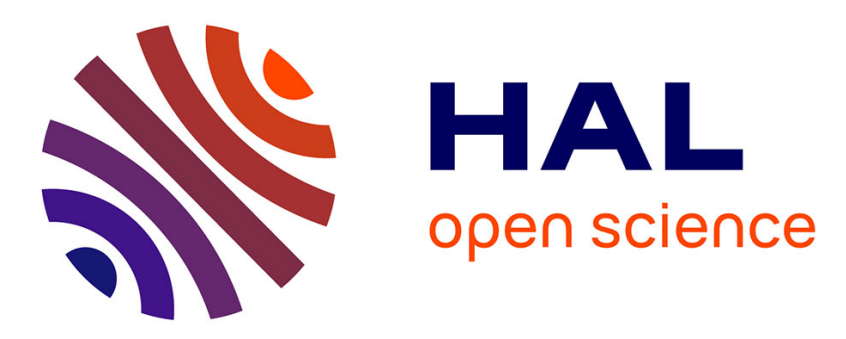

\title{
Applied Thermodynamics for Process Modeling in Catalytic Gas Phase Olefin Polymerization Reactors
}

Muhammad Ahsan Bashir, Vasileios Kanellopoulos, Mohammad Al-haj Ali, Timothy F.L. Mckenna

\section{- To cite this version:}

Muhammad Ahsan Bashir, Vasileios Kanellopoulos, Mohammad Al-haj Ali, Timothy F.L. Mckenna. Applied Thermodynamics for Process Modeling in Catalytic Gas Phase Olefin Polymerization Reactors. Macromolecular Reaction Engineering, 2019, pp.1900029. 10.1002/mren.201900029 . hal02414098

\author{
HAL Id: hal-02414098 \\ https://hal.science/hal-02414098
}

Submitted on 12 Nov 2020

HAL is a multi-disciplinary open access archive for the deposit and dissemination of scientific research documents, whether they are published or not. The documents may come from teaching and research institutions in France or abroad, or from public or private research centers.
L'archive ouverte pluridisciplinaire HAL, est destinée au dépôt et à la diffusion de documents scientifiques de niveau recherche, publiés ou non, émanant des établissements d'enseignement et de recherche français ou étrangers, des laboratoires publics ou privés. 


\title{
APPLIED THERMODYNAMICS FOR PROCESS MODELLING IN CATALYTIC GAS PHASE OLEFIN POLYMERIZATION REACTORS
}

\author{
Muhammad Ahsan Bashir* a), Vasileios Kanellopoulos ${ }^{\text {b) }}$, Mohammad Al-haj Ali ${ }^{\text {b) }}$, Timothy \\ F.L. McKenna ${ }^{a} *$ \\ *timothy.mckenna@univ-lyon1.fr \\ a) Université de Lyon, Univ. Lyon 1, CPE Lyon, CNRS, UMR 5265, Laboratoire de Chimie \\ Catalyse Polymères et Procédés (C2P2), \\ LCPP team, Bat 308F, 43 Bd du 11 novembre 1918, F-69616 Villeurbanne, France. \\ b) Process Development Group - Innovation Process Technology, Borealis Polymers PO \\ PDO, Borealis Polymers Oy - P. O. Box330 - Porvoo - Finland.
}

\begin{abstract}
The Sanchez-Lacombe Equation of State (SL EoS) is used to model the solubility of different industrial alkane penetrants in polyethylene to explain the importance of considering different diluents for different processes, and the impact that this choice can have on operating conditions, especially for the production of linear low density polyethylene (LLDPE). Extension of this approach to ternary (ethylene/penetrant/LLDPE) systems shows the effect of composition of penetrant/ethylene mixtures on the solubility of such mixtures in LLDPE and swelling of the polymer phase at conditions of industrial relevance. This analysis reveals that using a constant polymer density instead of that predicted by the SL EoS can result in erroneous calculations of the particle size distribution developments in an olefin polymerization reactor.
\end{abstract}

\section{Topical Heading}

Thermodynamics and Molecular-Scale Phenomena

\section{Keywords}

Olefin polymerization, applied thermodynamics, penetrants, solubility, swelling 


\section{Introduction}

Polyolefins are the most widely used plastics today due to their low production cost and wide range of applications (e.g., packaging and other disposables, building and construction, agriculture, appliances, transportation, electrics and electronics, furniture, communication, automotive, etc.). It is well acknowledged that the degree of technological and scientific sophistication in relation to the catalytic polyolefin manufacturing has no equal among other synthetic polymer production processes. Presently, the total polyolefins world-production exceeds 130 million tons per year covering around $45 \%$ of the total plastic production (about 1.5 times the steel consumption in volume). ${ }^{[1]}$

Polyethylene (including high-density polyethylene (HDPE), low-density polyethylene (LDPE) and linear low-density polyethylene (LLDPE)) and polypropylene (PP) cover $60 \%$ and $40 \%$ of the total polyolefins production, respectively. In the coming years, the annual POs world market growth is estimated to $4-6 \%{ }^{[1]}$.

The diversity of available polyolefin grades has been the result of advances in both the development of novel catalytic systems (e.g., Ziegler-Natta (Z-N), metallocenes, etc.) and the use of new reactor configurations (e.g., multi-stage reactors) and operating conditions. Current polyolefin manufacturing processes take advantage of high-yield catalysts and cascade-reactor technologies to produce polyolefins with desired molecular (e.g., bimodal molecular weight distribution, BMWD, copolymer composition distribution, $\mathrm{CCD}$, etc.) and morphological properties (i.e., particle size distribution, PSD) at a low production cost. The various catalytic polyolefin processes can be broadly classified into solution, slurry-phase and gas-phase processes. Note that almost $70 \%$ of the total polyolefins production is carried out in gas- and slurry-phase catalytic olefin polymerization processes. ${ }^{[1]}$ Each process has its 
advantages depending on the producer, their product goals and intellectual property considerations.

Gas-phase catalytic olefin polymerization is a highly attractive process since the polymerization is carried out in the absence of a liquid inventory. The vast majority of the LLPDE polymer grades is produced in gas phase processes, and more specifically in bubbling fluidized bed reactors $(\mathrm{FBR})^{[2]}$ mainly due to their heat transfer capabilities (i.e., sufficient removal of the heat produced due to exothermic polymerization reaction). ${ }^{[2]}$

In terms of developing an understanding how LLDPE is produced, considerable work has been carried out on modelling and simulation of gas phase industrial polymerization reactors. It is beyond the scope of this article to discuss the numerous articles dedicated to that topic over the past decades ${ }^{[3,4,5,6]}$. However, it has to be pointed out that despite the economic importance of LLDPE processes as well as the vast number of investigations related to gas phase reactors operation under condensed mode ${ }^{[7,8,9,10]}$, none of the modelling studies have directly incorporated the thermodynamic interactions between the penetrants and polymers in the system. Certain efforts were made to use equations of state to model individual penetrant solubilities in polyethylene (i.e. binary systems), ${ }^{[11,12,13,14]}$ and then treated individual solubilities as being independent and additives.

Consequently, one of the main points to emerge from the literature on thermodynamics or experimental investigation of ethylene polymerization over the last 15 years is that adding alkanes (and even $\alpha$-olefin comonomers) can have a significant impact on the thermodynamics of the polymerization systems, which in turn can impact the polymer structure and the operational stability of the reactor. For instance, it has been known that the presence of alkanes or alkenes can enhance the solubility of ethylene in LLDPE, while the presence of ethylene decreases the solubility of the heavier components in the polymer phase 
${ }^{[15,16]}$. It has been shown experimentally that adding alkanes in an olefin polymerization system has a pronounced effect on polymerization rate, catalyst mileage and polymer properties. ${ }^{[17,18,19]}$

In all the above-mentioned modelling efforts for catalytic olefin (co)-polymerizations, precise estimation of reaction kinetics is among the most important steps towards the accurate modelling and simulation of the reactor operation. The concentrations of the molecular species in the different phases present in the polymerization reactors, but also the physical properties of the swollen polymer phase can be estimated by employing different equations of state $(\mathrm{EoS})$ or activity coefficient models $(\mathrm{ACM}) .^{[2,12,20,21]}$ One of the more important physical properties in an olefin polymerization reactor is the density of the continuous phase mixture, which influences the selection of the gas phase fluidization conditions, the heat transfer capabilities, the solids content (and thus the space-time yield) inside the reactor as well as the product withdrawal rate. ${ }^{[12,22,23]}$ It has to be mentioned that most of the modelling studies presented so far in the literature, assume a constant value of the polymer density. Ignoring the multi-component feature of the reacting species (i.e., penetrants), results in ignoring the penetrants co-solubility effects that are strongly related to the changes of the free volume of the polymer as well as of the swelling of the polymer. In reality, the polymer particles inside a polymerization reactor are swollen due to the sorption of the penetrants (reactive or not!). Thus, the polymer density cannot be precisely estimated by considering a single constant value ${ }^{[24,25]}$ or by using a simplified temperature dependent polymer density function. ${ }^{[26]}$

The present work deals with the application of a thermodynamic model based on statistical mechanics; i.e., the Sanchez-Lacombe Equation of State (SL EoS ${ }^{[27]}$, to precisely estimate the densities of LLDPE under different conditions of swelling. The thermodynamic model is employed to estimate the solubilities of different penetrants in polyethylene as well as the 
degree of polymer swelling over a wide range of operating conditions. More specifically, the SL EoS is fitted using the available experimental solubility data of propane/polyethylene, isobutane/polyethylene and n-hexane/polyethylene binary systems over a wide range of temperatures and pressures. Based on these data, the swelling of the polymer phase caused by the dissolution of solvents is calculated by the fitted SL EoS. It should be pointed out that the binary interaction parameters used in the ternary mixture solubility estimation were obtained by fitting the SL EoS to the available experimental data of penetrant/polyethylene and ethylene/polyethylene binary systems. Subsequently, a comparison between the polymer phase density calculated by considering a constant polymer density and the one predicted by the SL EoS (which takes into account the swelling of polymer matrix) is presented with respect to particle size distribution in a gas phase reactor. The findings of the present work can be used to assess the application of different penetrants and process conditions in industrial polyolefin production processes and it finally demonstrates that the thermodynamic properties (i.e., solubility and polymer swelling) of mixtures can affect the physical and the morphological properties (i.e., particle size distribution (PSD)) of the system at conditions of industrial importance.

It is important to mention that for penetrant/polymer mixtures, polymer crystallinity has a strong influence on different physical and thermodynamic properties of the mixture, and the SL EoS assumes the polymer phase as totally amorphous. It has been shown by various authors $^{23-26}$ that properly fitted binary interaction parameters enable the SL EoS to estimate various thermodynamic properties of mixtures involving semi-crystalline polymers with an acceptable error (i.e., usually the error between experimental and fitted SL EoS values is less than 10\%). Therefore, in this work the binary interaction parameters of the SL EoS were tuned to account for the effect of polymer crystallinity on penetrant (i.e., penetrant and ethylene) sorption in the polymer, at different temperatures and pressures. 


\section{Modelling Part:}

\section{The Sanchez-Lacombe Equation of State}

Phase behavior and other thermo-physical properties of the mixtures containing one or more macromolecular components are different from non-polymeric fluids/mixtures. For the precise description of thermodynamic properties of such mixtures involving molecules of arbitrary size, Sanchez and Lacombe ${ }^{[27]}$ developed the lattice-fluid model, namely SanchezLacombe Equation of State (SL EoS). In the generalized form, for a pure component the SL EoS can be written as: ${ }^{[20,21,27,28]}$

$$
\overline{\rho_{i}^{2}}+\bar{P}_{i}+\overline{T_{i}}\left[\ln \left(1-\overline{\left.\rho_{i}\right)}+\left(1-\frac{1}{r_{i}}\right) \overline{\rho_{i}}\right]=0\right.
$$

Where $\bar{P}, \bar{T} \bar{\rho}$ and $r$ are the reduced pressure, reduced temperature, reduced density and the number of lattice sites occupied by the $i^{\text {th }}$ pure component, respectively. The relationship between the absolute and reduced properties of the $i^{\text {th }}$ component can be written as: ${ }^{\text {[27,28] }}$

$$
\overline{P_{i}}=\frac{P}{P_{i}^{*}}=\frac{P v_{i}^{*}}{\varepsilon_{i}^{*}}, \overline{T_{i}}=\frac{T}{T_{i}^{*}}=\frac{R T}{\varepsilon_{i}^{*}}, \overline{\rho_{i}}=\frac{\rho_{i}}{\rho_{i}^{*}}=\frac{r_{i} v_{i}^{*}}{v_{i}}, r_{i}=\frac{M_{i} P_{i}^{*}}{R T_{i}^{*} \rho_{i}^{*}}
$$

Where $P_{i}^{*}$ is the characteristic pressure, $v_{i}{ }^{*}$ is the closed packed mer volume, $\varepsilon_{i}{ }^{*}$ is the interaction energy per mer, $\mathrm{r}_{\mathrm{i}}$ is the segment number, $T_{i}^{*}$ is the characteristic temperature and $\rho_{i}^{*}$ is the characteristic density of $i^{\text {th }}$ component. Further details about the derivation, fitting of the model equations to solubility data and obtaining the penetrant mass fraction in the mixture from SL EoS can be found in references [29,30]. The swollen polymer-phase density, 
$\rho$, in case of binary and multi-component systems can be obtained by the following relationship: ${ }^{[20,21,27,28,31]}$

$$
\rho=\rho^{*} \times \bar{\rho}=\left(\frac{1}{\sum_{i=1}^{n} \frac{m_{i}}{\rho_{i}^{*}}}\right) \times \bar{\rho}
$$

where, ' $n$ ' is the number of components in the mixture, $m_{i}$ is the mass fraction of $i^{\text {th }}$ component in the mixture obtained by solving SL EoS, $\rho_{i}^{*}$ is characteristic density of the $i^{\text {th }}$ component and $\bar{\rho}$ is the reduced mixture density obtained by solving the SL EoS. Using this mixture density, swelling of the polymer can be calculated by:

$$
\% \text { swelling }=100 \times\left(\frac{1}{\left(\rho \times x_{P} \times \dot{V}_{P}\right)}-1\right)
$$

Where, $x_{p}$ is the polymer mass fraction in the mixture and $\dot{V}_{P}$ is the specific volume of pure polymer $\left(\mathrm{m}^{3} / \mathrm{kg}\right){ }^{[32,33]}$ It should be noted that in case of binary systems subscripts 1 denotes the penetrant and subscript 2 denotes the polymer, whereas, subscripts 1,2 and 3 (or $P$ ) are used for penetrant, ethylene and polymer in the ternary systems, respectively in this work. Table 1 shows the SL EoS characteristic parameters used for different penetrants, ethylene and polyethylene types used in this work. 
Table 1. Pure component characteristic parameters of SL EoS used in this work.

\begin{tabular}{lcccc}
\hline Component & $\mathbf{T}^{*}(\mathbf{K})$ & $\mathbf{P}^{*}(\mathbf{b a r})$ & $\boldsymbol{\rho}^{*}\left(\mathbf{k g} / \mathbf{m}^{\mathbf{3}}\right)$ & Reference \\
\hline Ethylene & 283 & 3395 & 680 & {$[34]$} \\
Propane & 371 & 3140 & 690 & {$[21]$} \\
i-Butane & 398 & 2880 & 720 & {$[21]$} \\
n-Hexane & 476 & 2980 & 775 & {$[21]$} \\
HDPE & 650 & 4250 & 905 & {$[34]$} \\
LLDPE-1-hexene & 653 & 4360 & 903 & {$[34]$} \\
\hline
\end{tabular}

\section{Results and Discussion}

\section{1- Binary system:}

\section{1- Solubility of Penetrants in Polyethylene}

The experimental solubility data of various penetrants in polyethylene, which are commonly used in the industrial polyolefins production processes, at different conditions are shown in

\section{Table 2.}

Table 2. Penetrant/PE binary systems considered in this work.

\begin{tabular}{lccc}
\hline Penetrant/PE & $\begin{array}{c}\text { Temperature range } \\
\left({ }^{\circ} \mathbf{C}\right)\end{array}$ & $\begin{array}{c}\text { Polymer crystallinity } \\
(\boldsymbol{\%} \mathbf{w t})\end{array}$ & Reference \\
\hline Propane/HDPE & $149-260$ & - & {$[35]$} \\
Propane/LLDPE & 70 & 56 & {$[36]$} \\
i-C4/HDPE & $66-94$ & 76 & {$[37]$} \\
i-C4/LLDPE & $66-94$ & 69 & {$[37]$} \\
n-C6/LLDPE & $70-90$ & 72 & {$[38]$} \\
\hline
\end{tabular}


Figures 1 to 4 depict the comparison of solubility values for various penetrants (i.e., propane, iso-butane, n-hexane) in polyethylene obtained by the fitted SL EoS with the available experimental data. It can be seen that the SL EoS values are in very good agreement with the corresponding experimental data over a wide range of operating conditions. It should be pointed out that a single binary interaction parameter $\left(k_{i j}\right)$ is used to fit the SL EoS model with the experimental data. It is important to point out that the value of $k_{i j}$ was almost independent of temperature for all the studied systems except propane/HDPE at elevated temperatures (i.e., above $140{ }^{\circ} \mathrm{C}$ ) where it shows a linear decrease with respect to temperature. Different $k_{i j}$ values for the different systems (e.g.,i-C4/HDPE and i-C4/LLDPE shown in Figure $2 \& 3$, respectively) at the same temperature can be attributed to differences in polyolefin properties e.g., polymer crystallinity in particular, and to the differences in characteristic parameters of SL EoS (see Table 1). ${ }^{\left[{ }^{30]}\right.}$ Based on Figures 1-4 it is apparent that the solubility of each penetrant in polyethylene decreases with the increase in temperature and increases with increasing pressure and carbon number of alkane. 


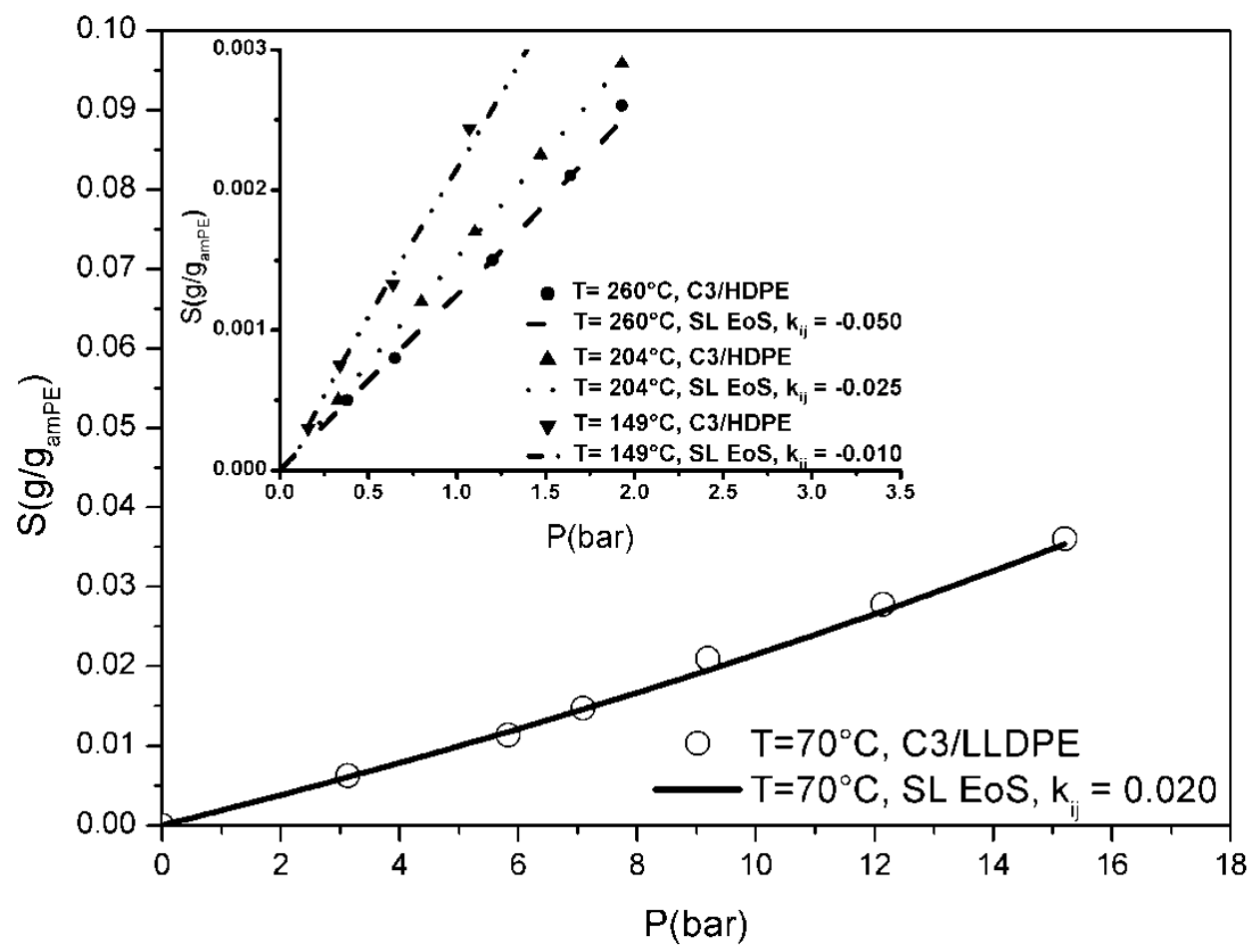

Figure 1. Solubility of propane in LLDPE at different temperatures. Experimental data at $70^{\circ} \mathrm{C}$ was obtained from ref. 36 whereas ref. 35 was used for high temperature experimental data.

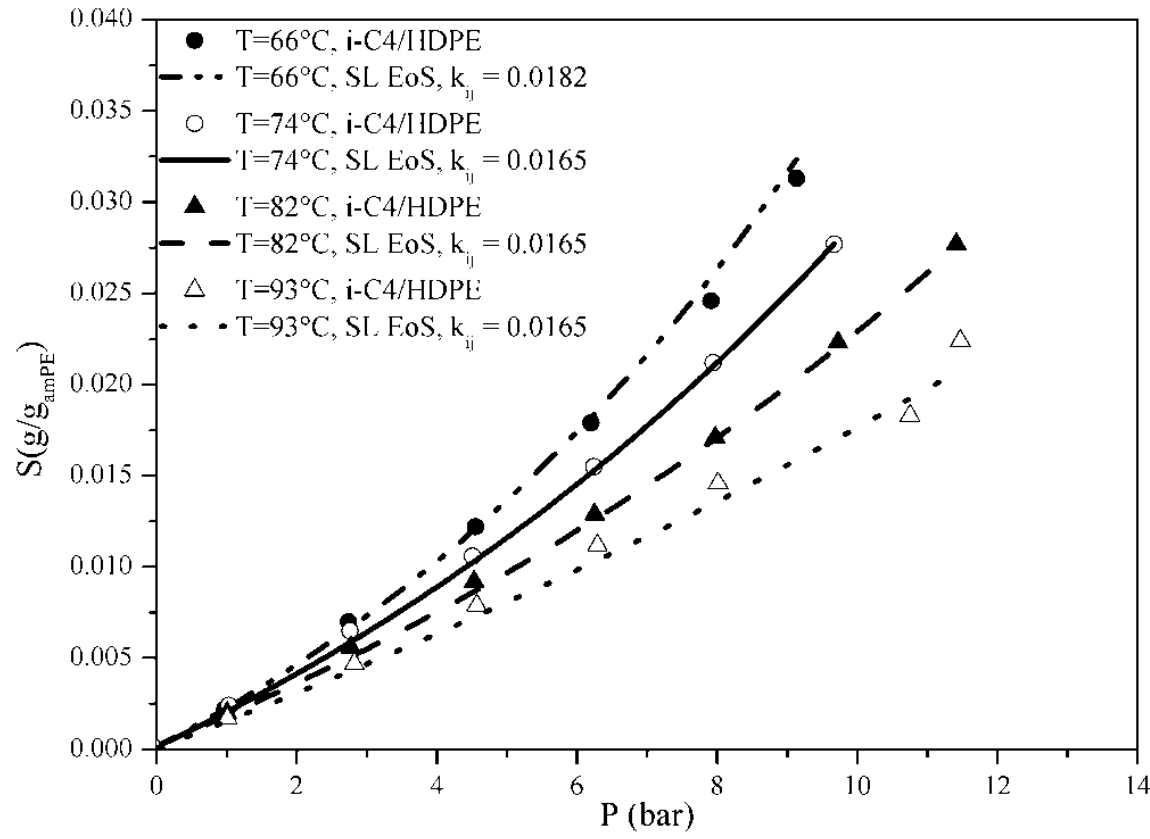

Figure 2. Solubility of iso-butane in HDPE at different temperatures. Experimental data was obtained from ref. 37. 


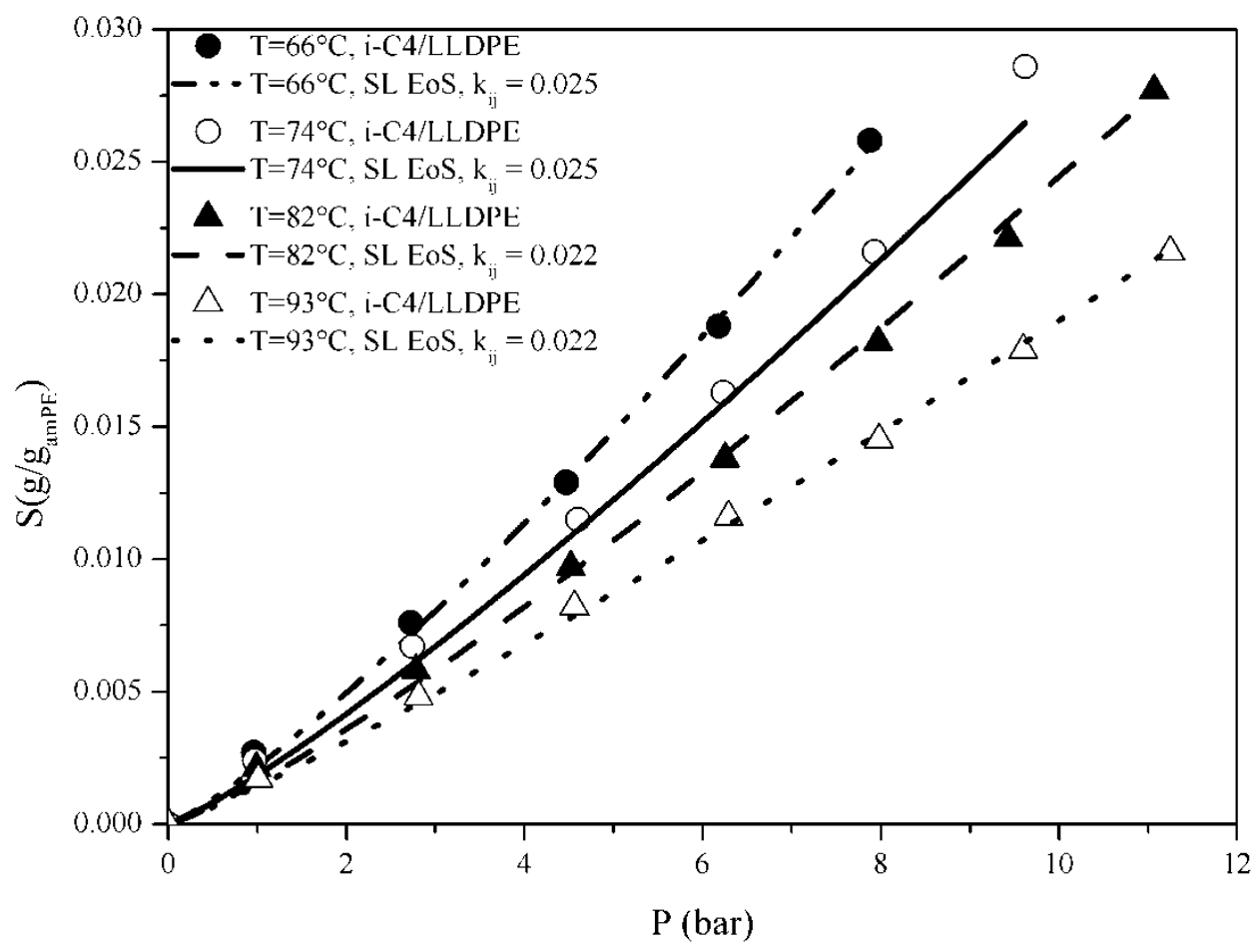

Figure 3. Solubility of iso-butane in LLDPE at different temperatures. Experimental data was obtained from ref. 37.

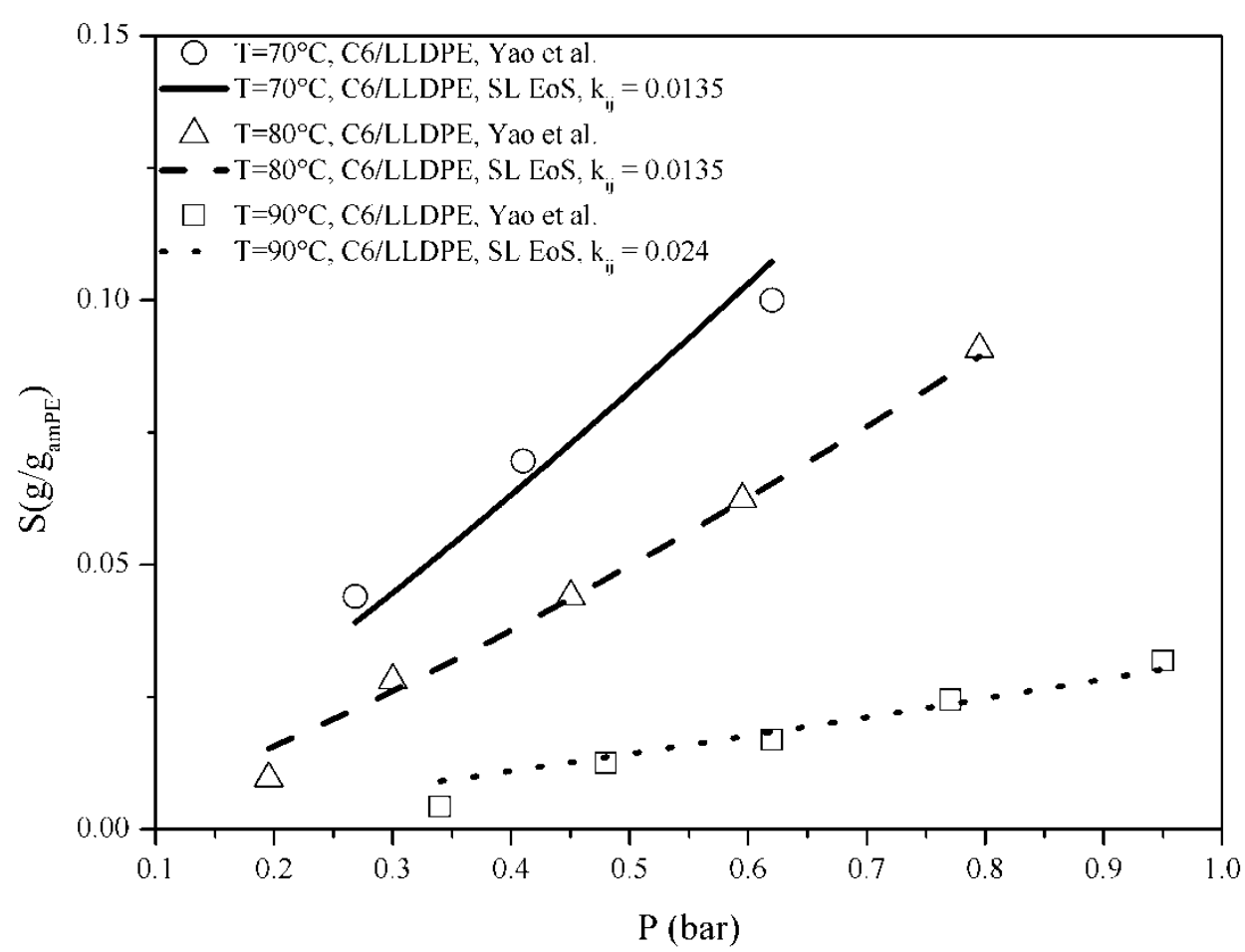

Figure 4. Solubility of n-hexane in LLDPE at different temperatures. Experimental data was obtained from ref. 38.

\subsection{Swelling of Polyethylene by Different Penetrants}

Due to the uptake of penetrant mass by the amorphous polymer phase, the volume of the polymer increases during polymerization. In the present study, the degree of polymer 
swelling due to the dissolution of the penetrant molecules in the polymer phase was calculated by using the Equation 4. Figures 5 to 7 illustrate the comparison of LLDPE swelling caused by propane, iso-butane and n-hexane in the temperature range of 70 to $90^{\circ} \mathrm{C}$. It can be seen that heavier alkanes cause higher swelling of polyethylene as compared to lower alkanes at a given temperature and pressure due to their higher affinity towards polyethylene matrix. For example, at $70^{\circ} \mathrm{C}, 8 \%$ of LLDPE swelling is caused by 0.4 bar of nhexane, 5.0 bar of iso-butane and 10.5 bar of propane, respectively (see Figure 5).

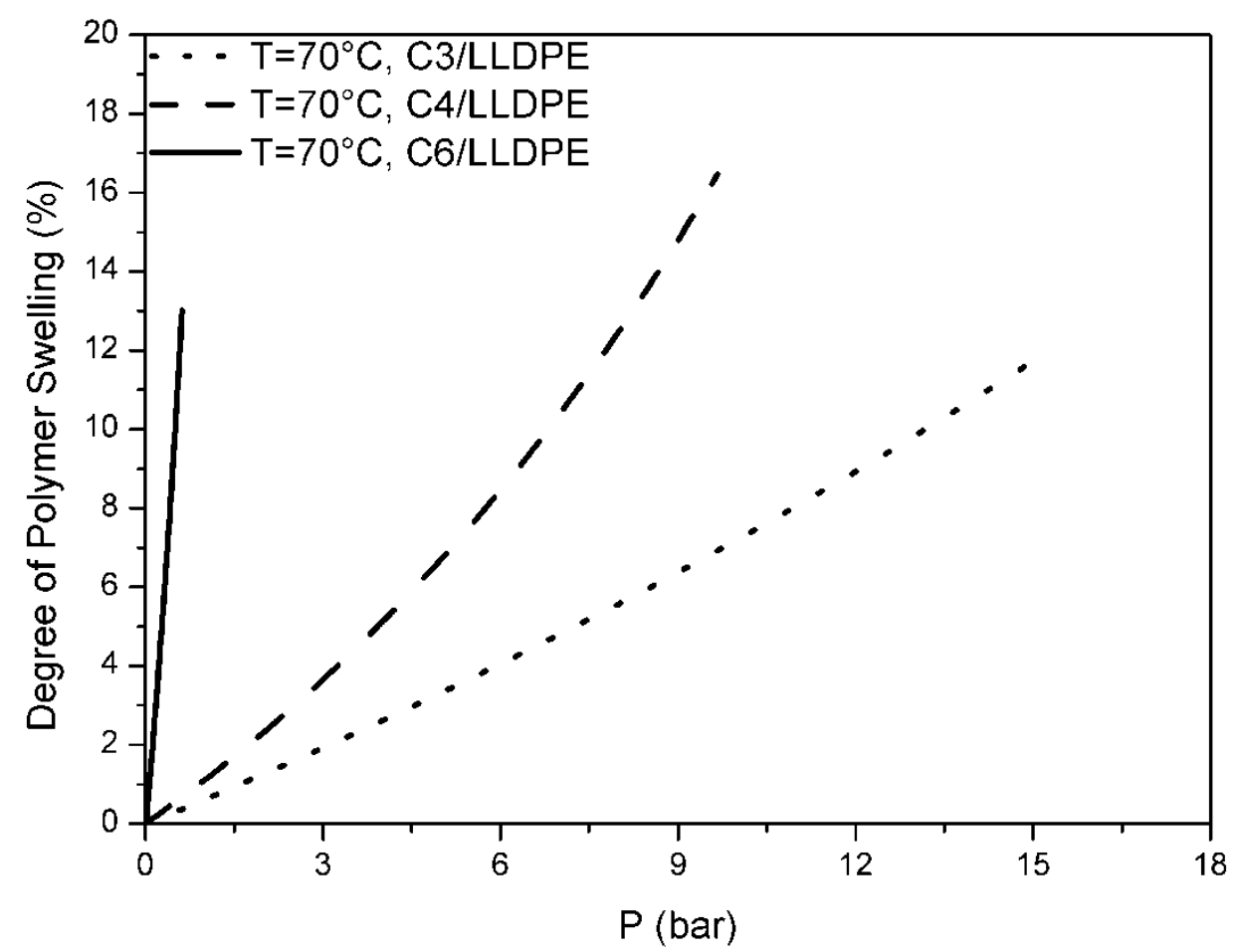

Figure 5. Degree of LLDPE swelling caused by the sorption of various penetrants at $70^{\circ} \mathrm{C}$. 


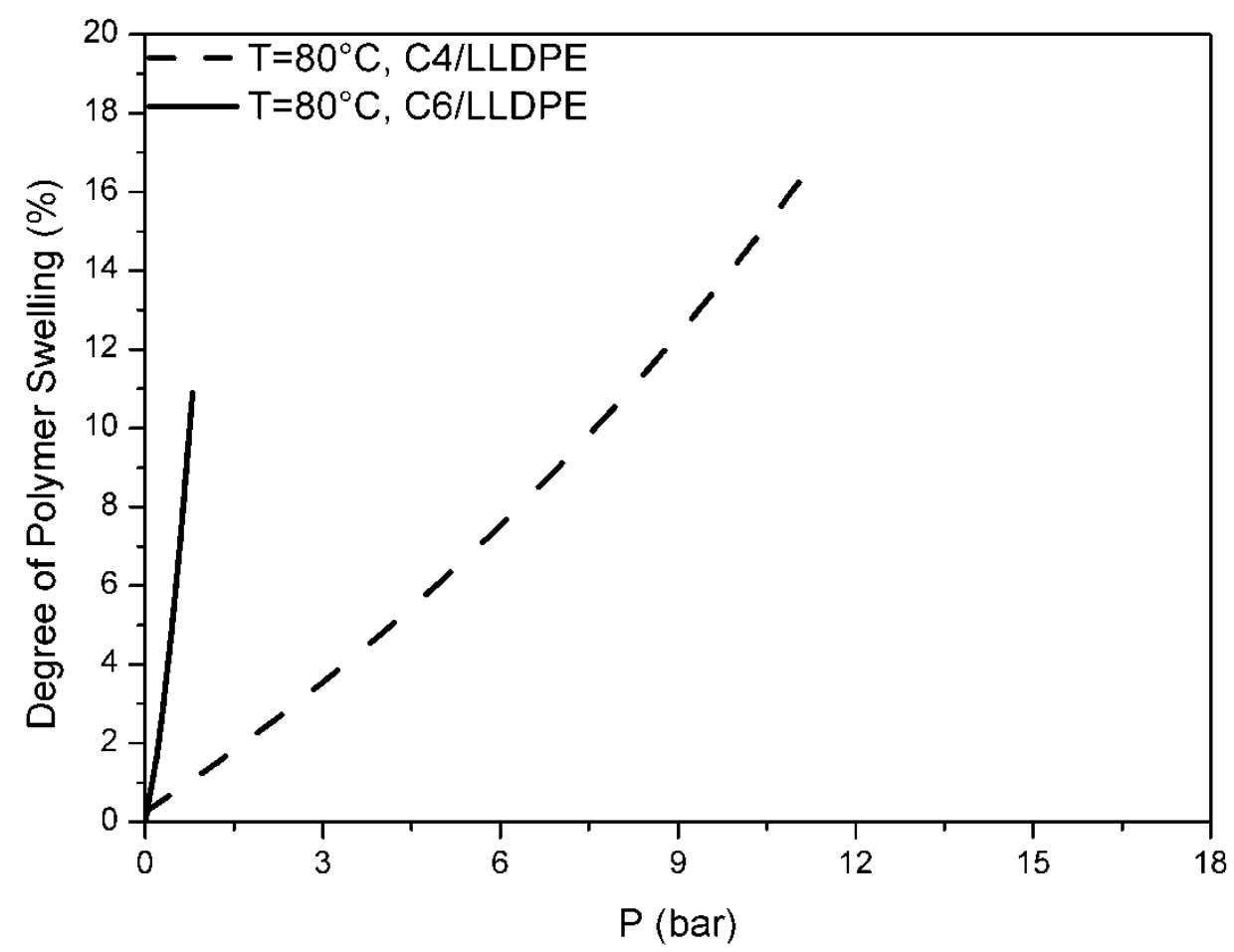

Figure 6. Degree of LLDPE swelling caused by the sorption of various penetrants at $80^{\circ} \mathrm{C}$.

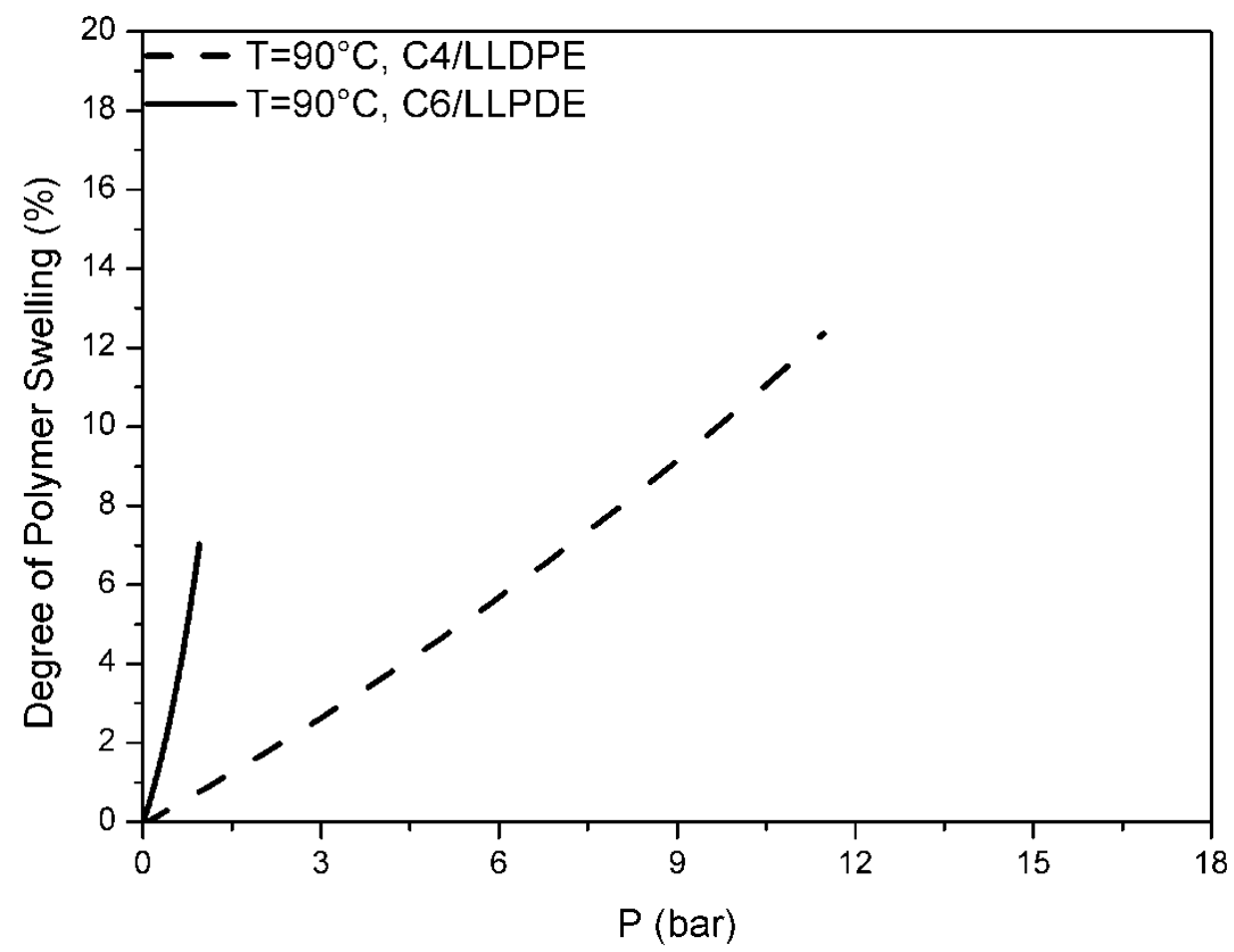

Figure 7. Degree of LLDPE swelling caused by the sorption of various penetrants at $90^{\circ} \mathrm{C}$.

\section{Ternary Systems:}


While binary systems are relatively easy to evaluate experimentally, the reaction medium of a typical production process consists of a number of components (e.g., monomer, comonomer, penetrant, chain transfer agents, etc.), thus, forming a multicomponent system. One of the main challenges in this sense is the lack of experimental data for relevant multicomponent systems. Limited ternary data ( 2 penetrants + LLDPE) is available, but for 4 or more components no experimental data is found in the open literature. The current article is limited to a treatment of ternary systems, but it should be evident that the extension of the same concepts to 4 or more components will have similar repercussions.

The use of SL EoS to estimate the multi-component mixture solubility (component $1 /$ component 2 /polymer 3 ) from the correspoding binary mixtures (component 1 /polymer or component 2/polymer) is well described elsewhere. ${ }^{[29]}$ According to the proposed methodology the binary experimental solubility data of ethylene/polyethylene and penetrant/polyethylene at $70^{\circ} \mathrm{C}$ and $90^{\circ} \mathrm{C}$ were first fitted with the SL EoS to obtain the respective binary interaction parameters $\left(k_{i j}\right)$. Those fitted $k_{i j}$ values were then used to estimate the multi-component solubility of ethylene/penetrant mixtures in polyethylene at various temperatures. Subsequently, the degree of polymer swelling caused by the sorption of the multicomponent mixture of penetrants and the polymer phase density can be calculated for each of the studied systems (i.e., propane/ethylene/PE, iso-butane/ethylene/PE, nhexane/ethylene/PE), with the later being useful in correct estimation of PSD of growing polyolefin particles inside the reactor. The estimation of such properties/parameters is of paramount importance for the operation of the industrial scale polyolefin production processes since they are strongly related to the operability (e.g., productivity, production split between the polymerization reactors, pressure developments, product removal valves sequence, etc.) as well as to the performance (e.g., hydrodynamic stability, mixing paterns, etc.) of the reactors. 


\subsection{SL EoS Cosolubility Estimations for Ternary systems}

The estimation of a multi-component mixtures solubility (i.e., ternary system consisting of penetrant(1)/ethylene(2)/polyethylene(3)) using the SL EoS model requires the use of two binary interaction parameters (i.e., $k_{13}$ and $k_{23}$ ). It should be mentioned that the values of $k_{13}$ used for each penetrant/PE system were obtained from the corresponding binary systems discussed in the previous sections, while the values of $k_{23}$ were obtained by fitting the SL EoS with the available experimental binary ethylene/PE solubility data.

Figures 8-12 illustrate the binary and multi-component solubilities of the studied systems at different conditions. It is apparent that the multi-component solubility of the penetrant/ethylene system in the polymer is between the binary solubilities of ethylene and penetrant, respectively at each studied temperature and feed composition. It should be pointed out that by increasing the ethylene feed content, the multi-component mixture solubility curves shift towards the binary ethylene/polymer mixture solubility curve at all temperatures and pressures. In addition, it is worth mentioning that the penetrant acts as a co-solvent for the low molecular weight penetrant (i.e., ethylene), while ethylene behaves as an anti-solvent for the high molecular weight component (i.e., penetrant) of the multi-component penetrants' mixture. The anti-solvent and co-solvent effects of each penetrant involved in the ternary system are best understood in terms of mass fraction of each component dissolved in the polymer phase as estimated by the SL EoS but for the sake of brevity, those figures are not shown here. However, similar data has been published in reference $\left[{ }^{39}\right]$. In this context, it was found that, among the studied systems, the strongest anti-solvent effect was shown in the multi-component system involving n-hexane. As an example, by increasing the ethylene feed concentration from $0 \mathrm{~mol} \%$ to $15 \mathrm{~mol} \%$, at 0.6 bar and $70{ }^{\circ} \mathrm{C}$ the concentration of $\mathrm{n}$-hexane in the polymer phase (expressed in grams per cubic centimeter of amorphous LLDPE) is 
reduced by approximately $73 \%$, see Figure 11. It was also concluded that the anti-solvent effect of ethylene on the solubility of all the studied penetrants increased with increase in temperature.

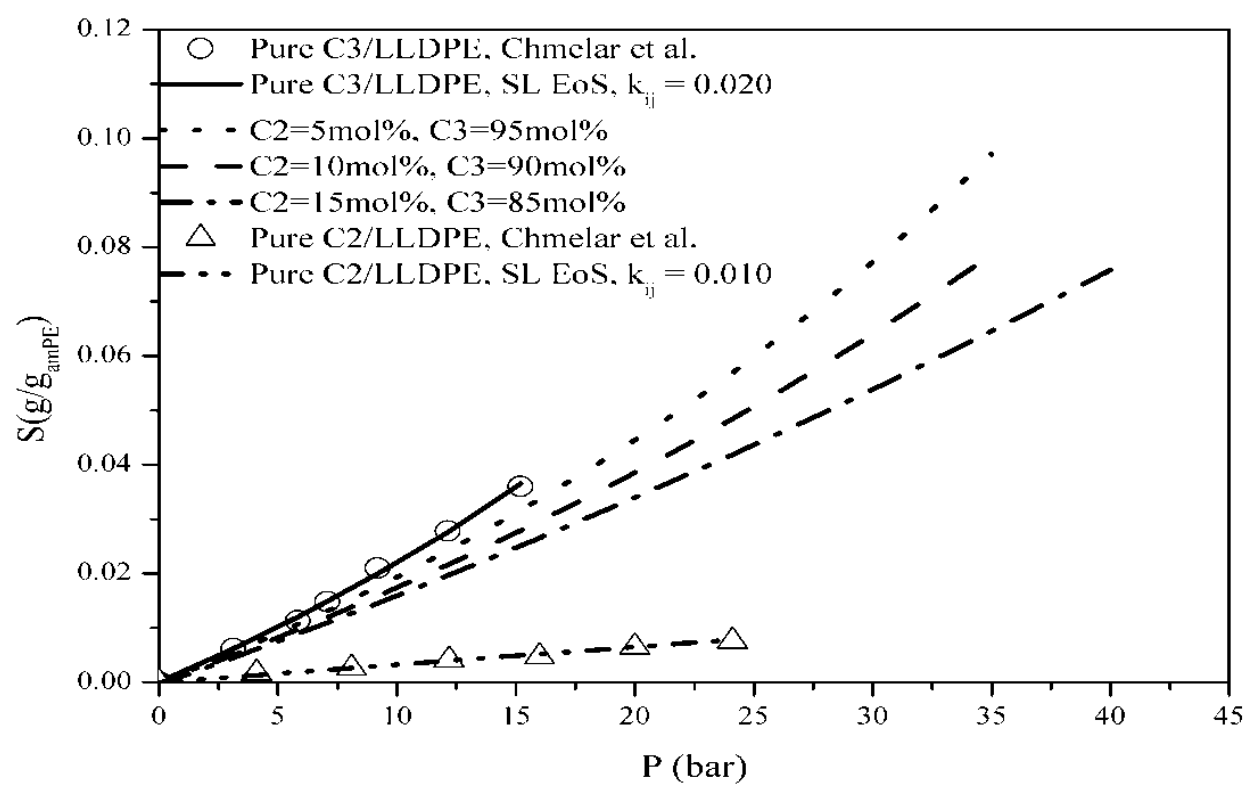

Figure 8. Solubility of propane, ethylene and their mixtures in LLDPE at $70{ }^{\circ} \mathrm{C} .^{[36]}$

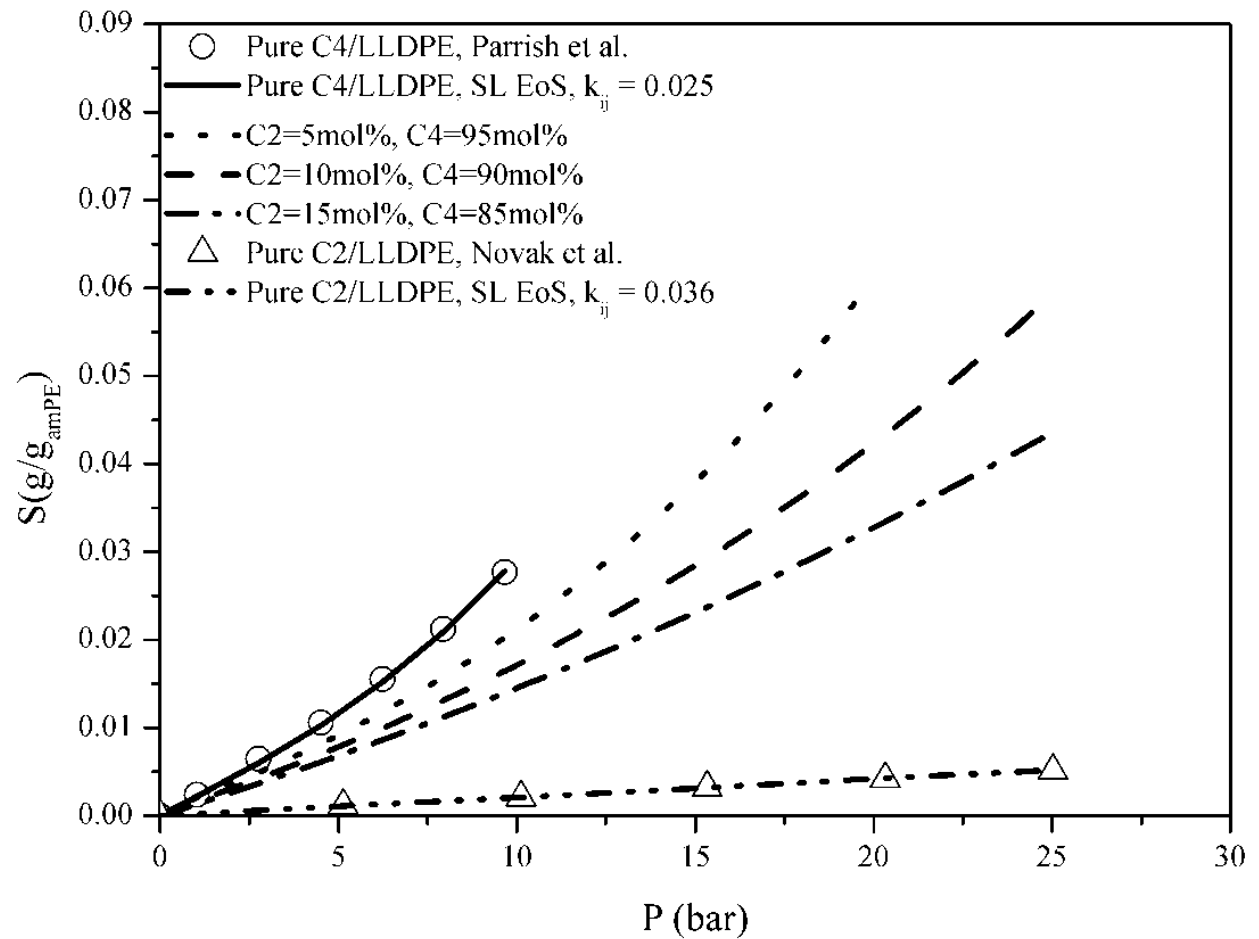

Figure 9. Solubility of iso-butane, ethylene and their mixtures in LLDPE at $74{ }^{\circ} \mathrm{C} .{ }^{[16]}$ 


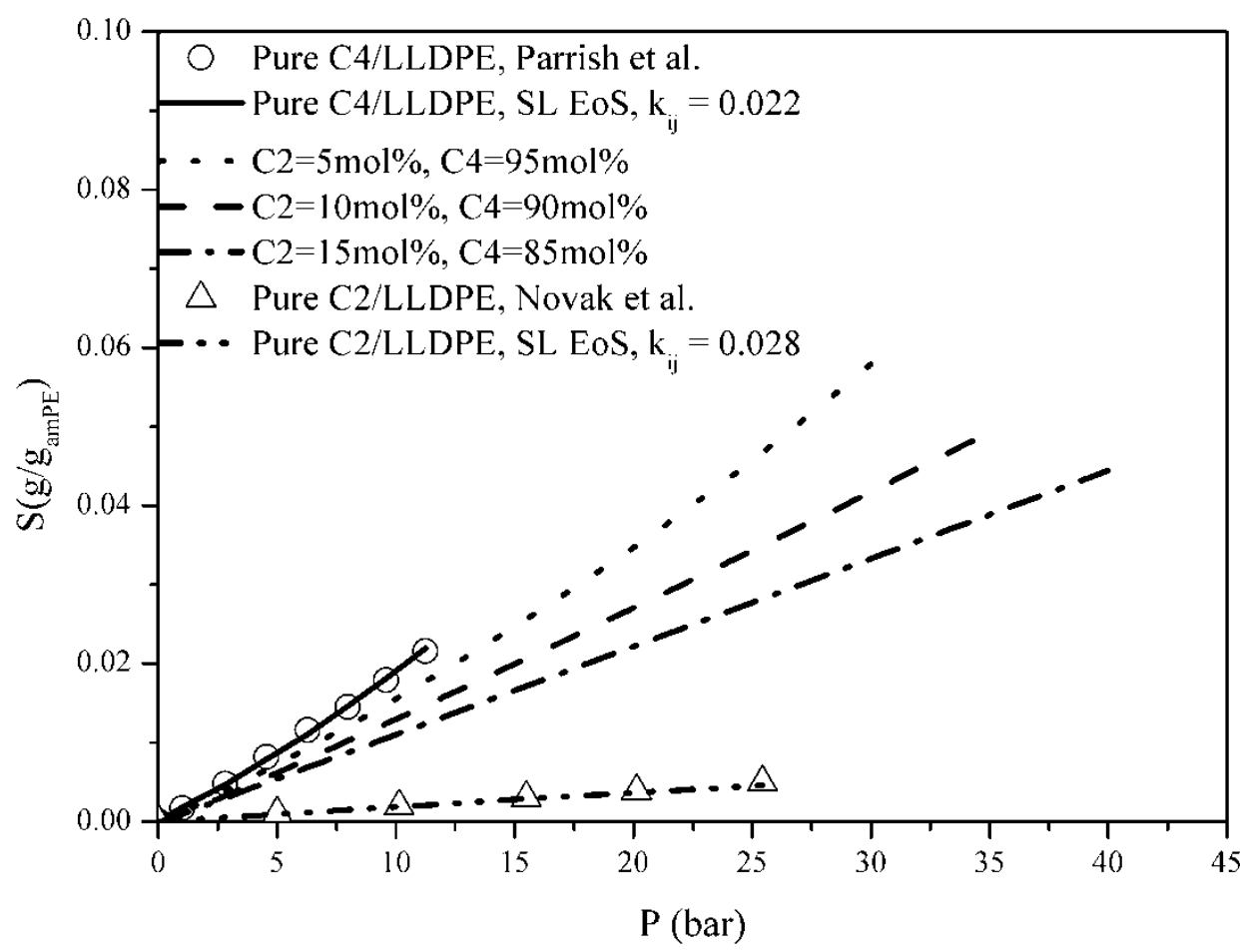

Figure 10. Solubility of iso-butane, ethylene and their mixtures in LLDPE at $93{ }^{\circ} \mathrm{C}$. ${ }^{[16]}$

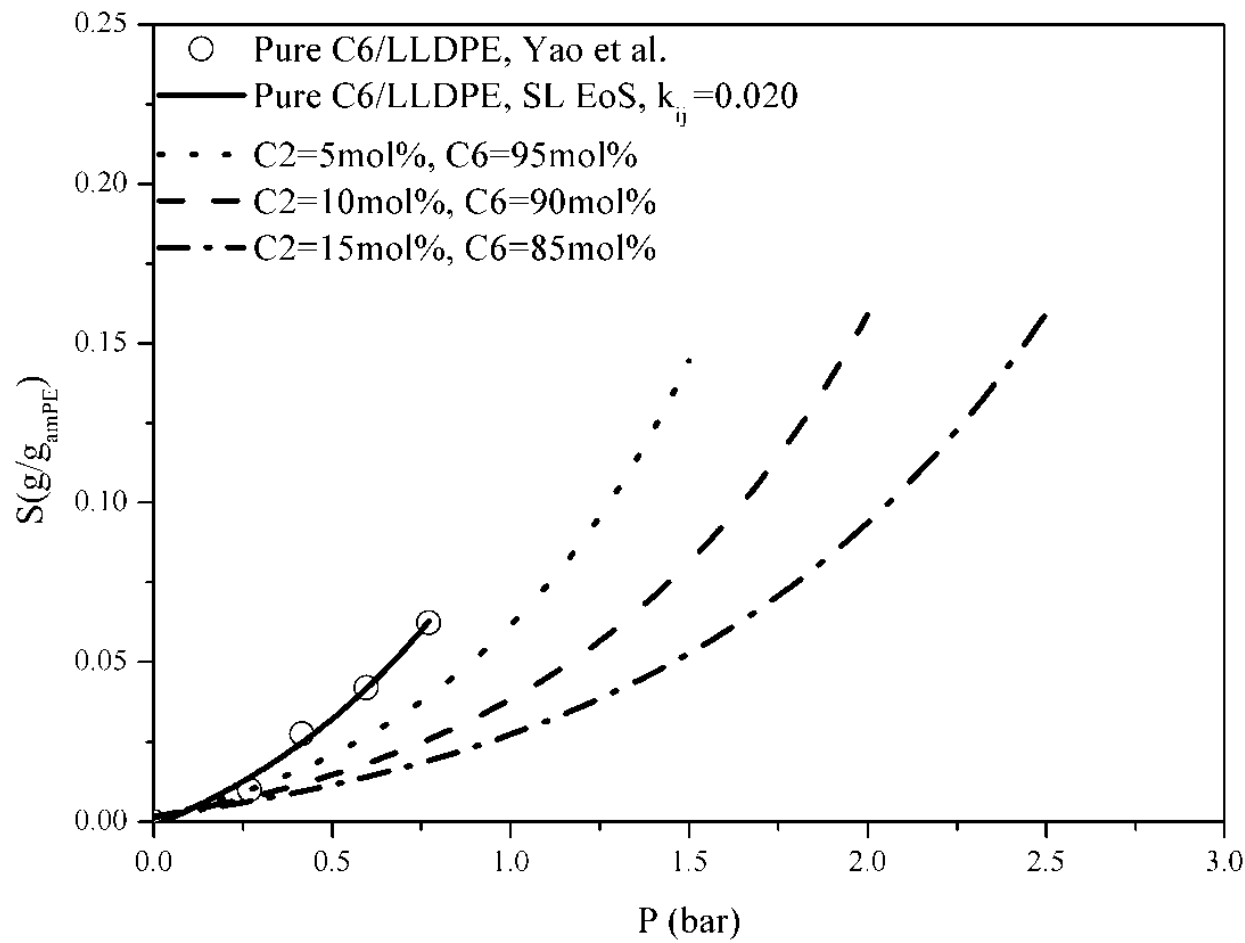

Figure 11. Solubility of n-hexane and n-hexane/ethylene mixtures in LLDPE at $70{ }^{\circ} \mathrm{C} .{ }^{[38]}$ 


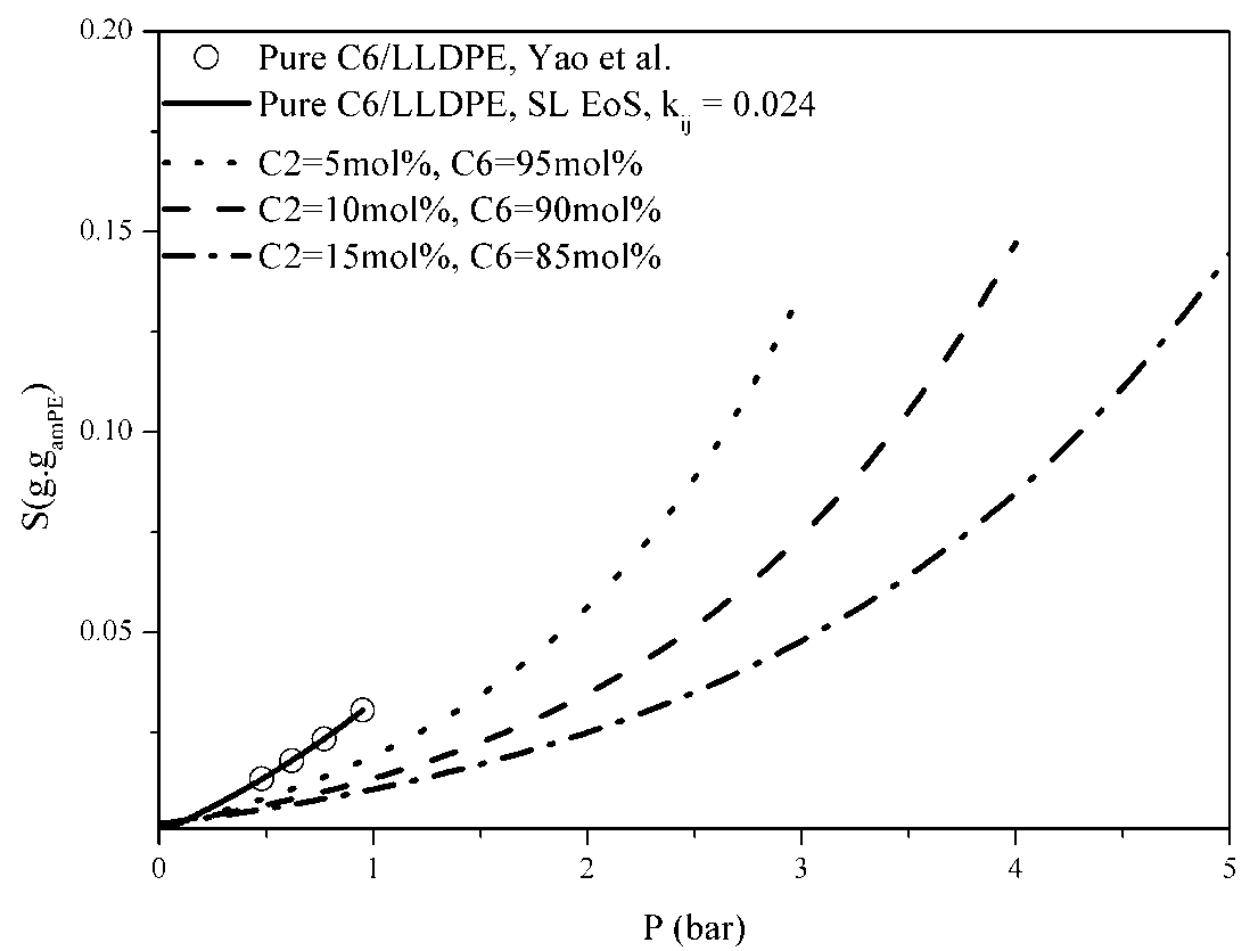

Figure 12. Solubility of n-hexane and n-hexane/ethylene mixtures in LLDPE at $90{ }^{\circ} \mathrm{C} .{ }^{[38]}$

\subsection{SL EoS Swelling Predictions for Ternary systems}

The degree of LLDPE swelling during the sorption of various penetrant/ethylene mixtures was calculated by using SL EoS and the results are presented in Figures 13-17. Note that the swelling curves exhibit a similar dependence on pressure and temperature as the solubility isotherms of the corresponding multi-component mixtures. It can be seen that the degree of swelling of LLDPE due to a binary mixture sorption (i.e., penetrant/ethylene) is less than that caused by the sorption of a pure penetrant and higher than pure ethylene at each temperature and pressure. Moreover, increasing the ethylene feed content decreases the degree of polymer swelling. In particular, for ethylene feed composition equal to $15 \mathrm{~mol} \%, 5 \%$ polymer swelling is caused by propane/ethylene mixture at $70^{\circ} \mathrm{C}$ and 10 bar pressure, while for the composition and conditions in n-hexane/ethylene mixture the same degree of polymer swelling is caused at a substantially lower pressure of $\sim 0.9$ bar (c.f. Figures 13 and 16). It should also be noted that in case of propane/ethylene mixtures, swelling of LLDPE becomes significant (i.e., $>5 \%$ ) at pressures above 15 bar for all feed compositions, whereas, in case of 
iso-butane or n-hexane significant swelling (i.e., >5\%) can occur below 10 bar depending on the temperature.

Chmelar et al., ${ }^{[36]}$ showed that decrease in softening point of LLDPE can occur due to the high degree of polymer swelling caused by the sorption of higher $\alpha$-olefins (i.e., 1-butene and 1-hexene) at $70{ }^{\circ} \mathrm{C}$. Such a decrease in softening point of LLDPE can cause significant particle agglomeration as well as sheeting and chunking phenomena which have a dramatic effect on the operability and performance of the polymerization reactors. ${ }^{[36]}$ Based on the results presented above, it can be concluded that that propane causes the lowest LLDPE softening (lowest degree of polymer swelling), while n-hexane causes the highest softening of LLDPE (highest degree of polymer swelling) in the temperature range of industrial relevance.

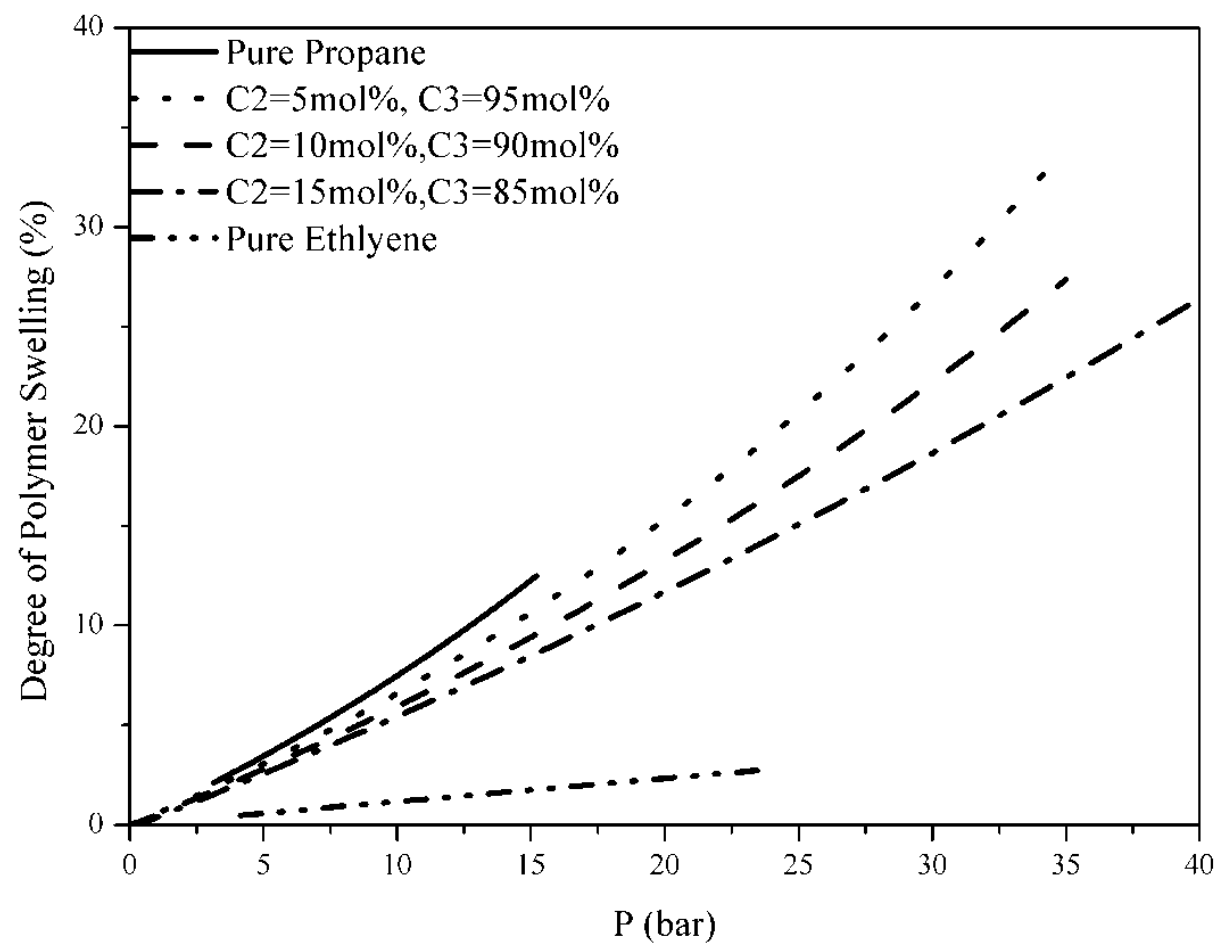

Figure 13. Degree of swelling of LLDPE during sorption of propane/ethylene mixture at 70 ${ }^{\circ} \mathrm{C}$. 


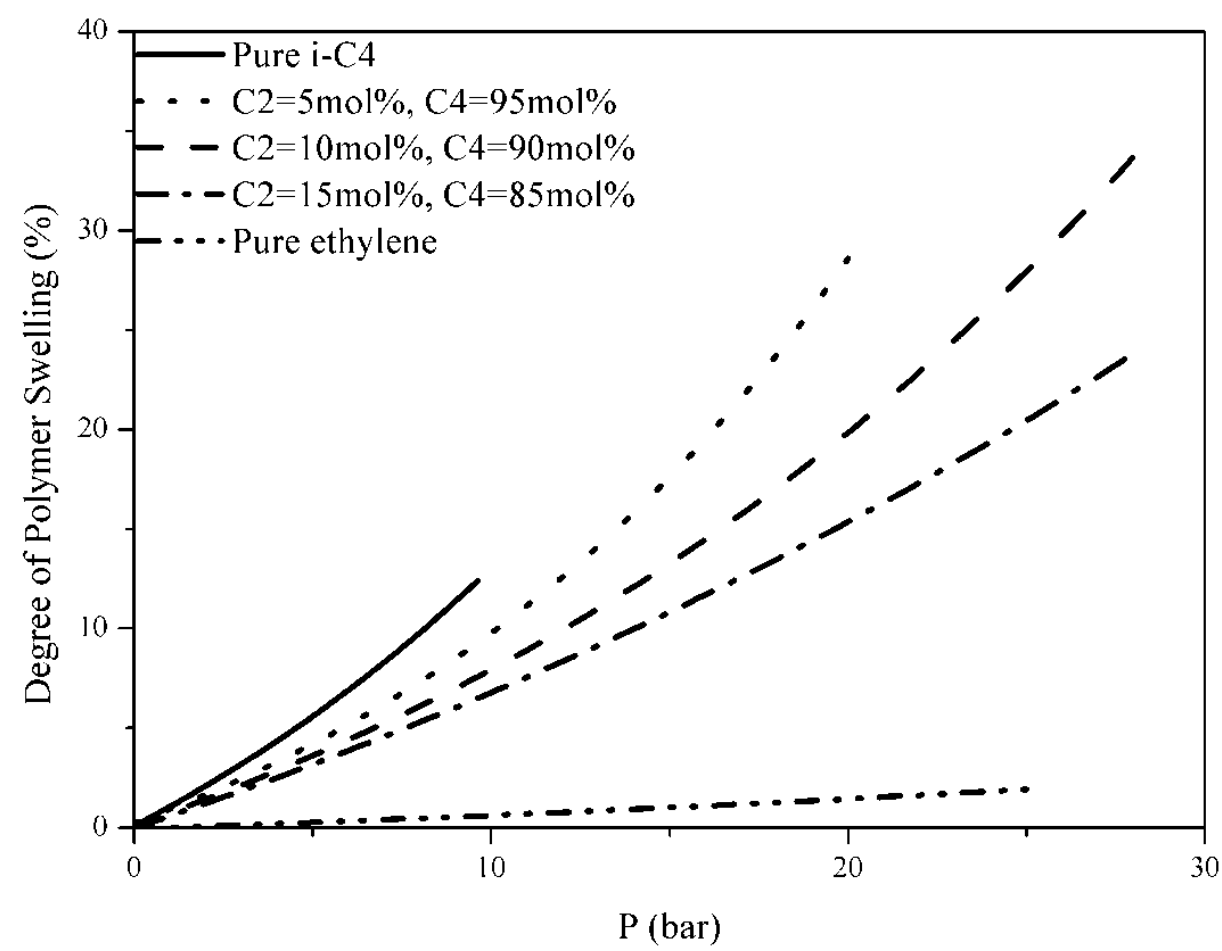

Figure 14. Degree of swelling of LLDPE during sorption of iso-butane/ethylene mixture at 74 ${ }^{\circ} \mathrm{C}$.

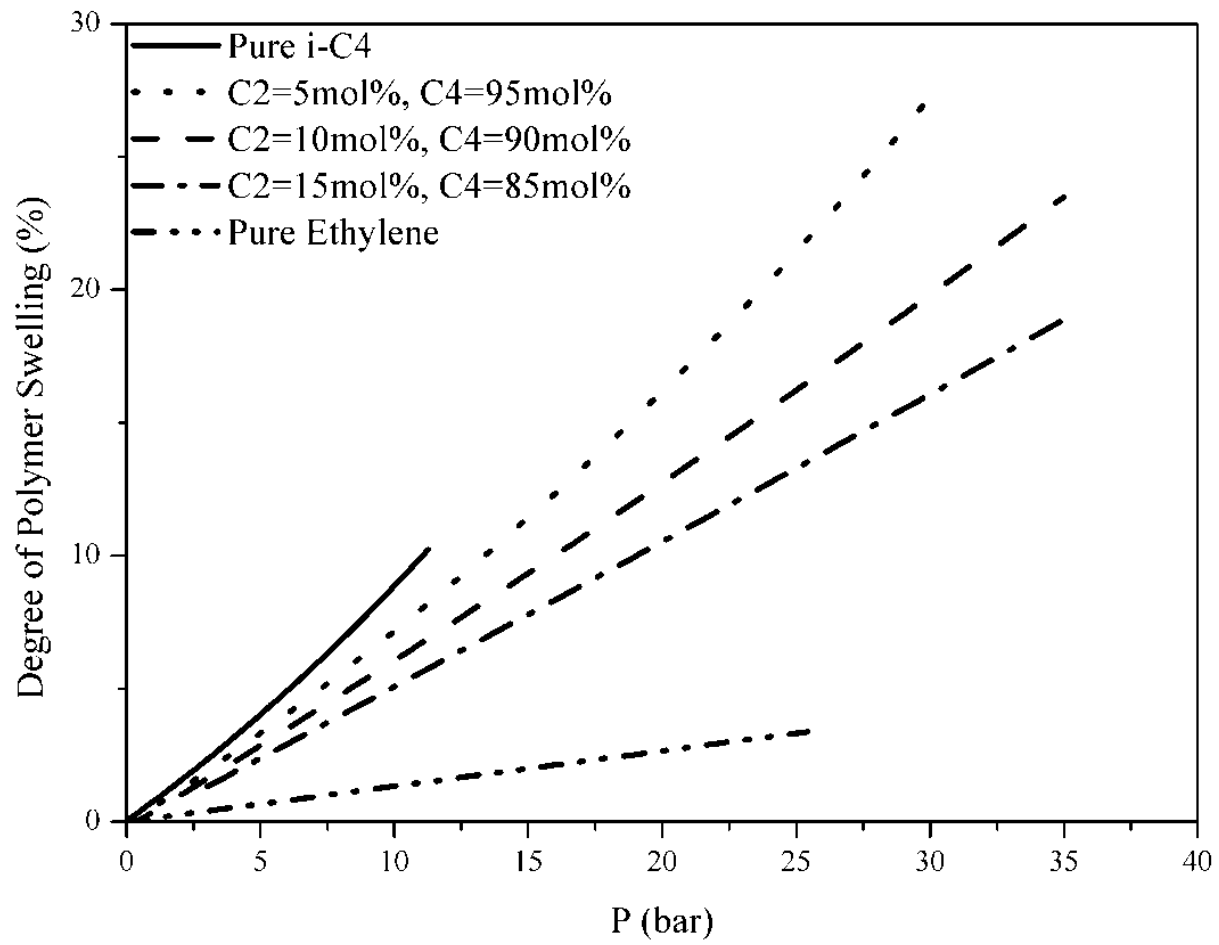

Figure 15. Degree of swelling of LLDPE during sorption of iso-butane/ethylene mixture at 93 ${ }^{\circ} \mathrm{C}$. 


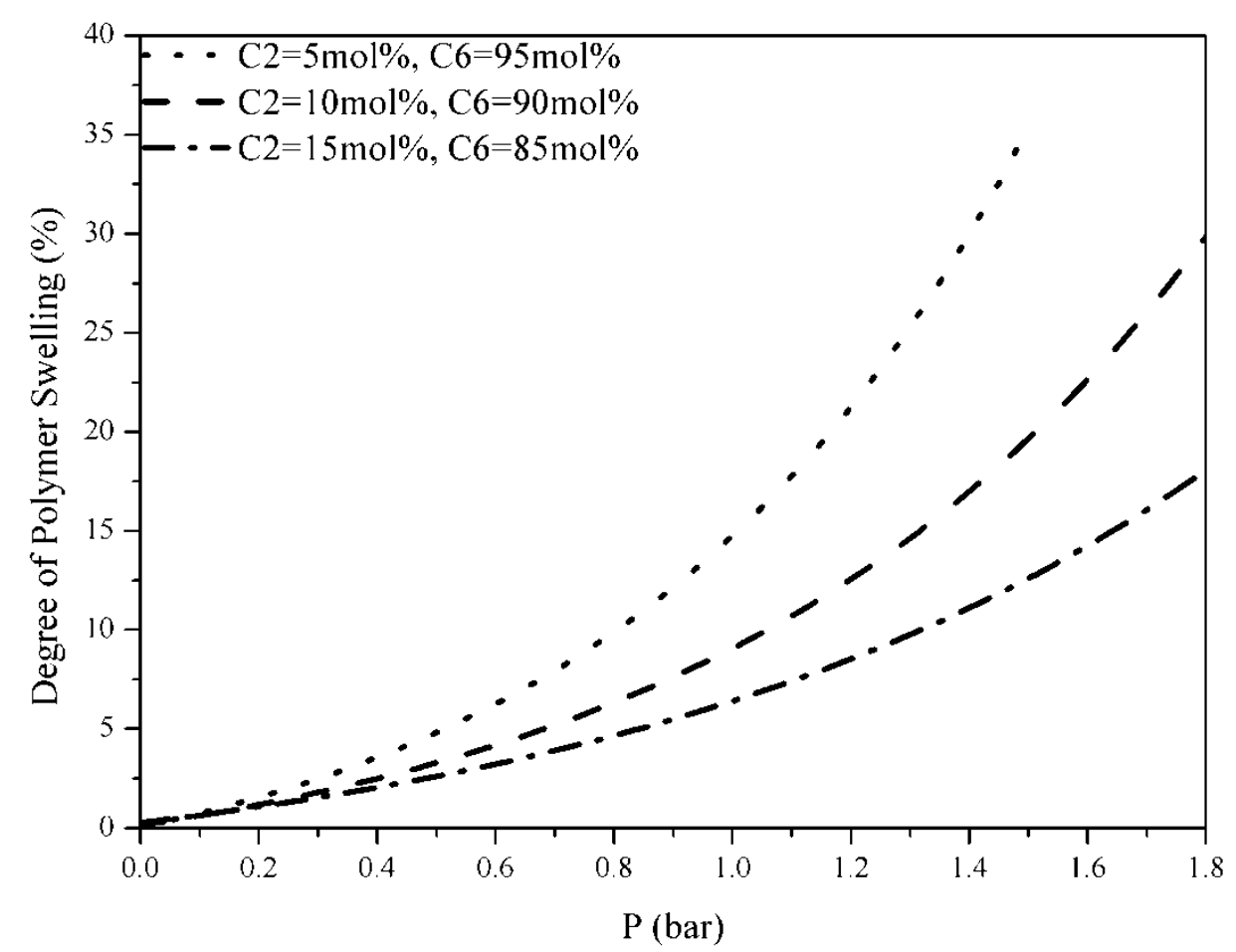

Figure 16. Degree of swelling of LLDPE during sorption of n-hexane/ethylene mixture at 7 $0^{\circ} \mathrm{C}$.

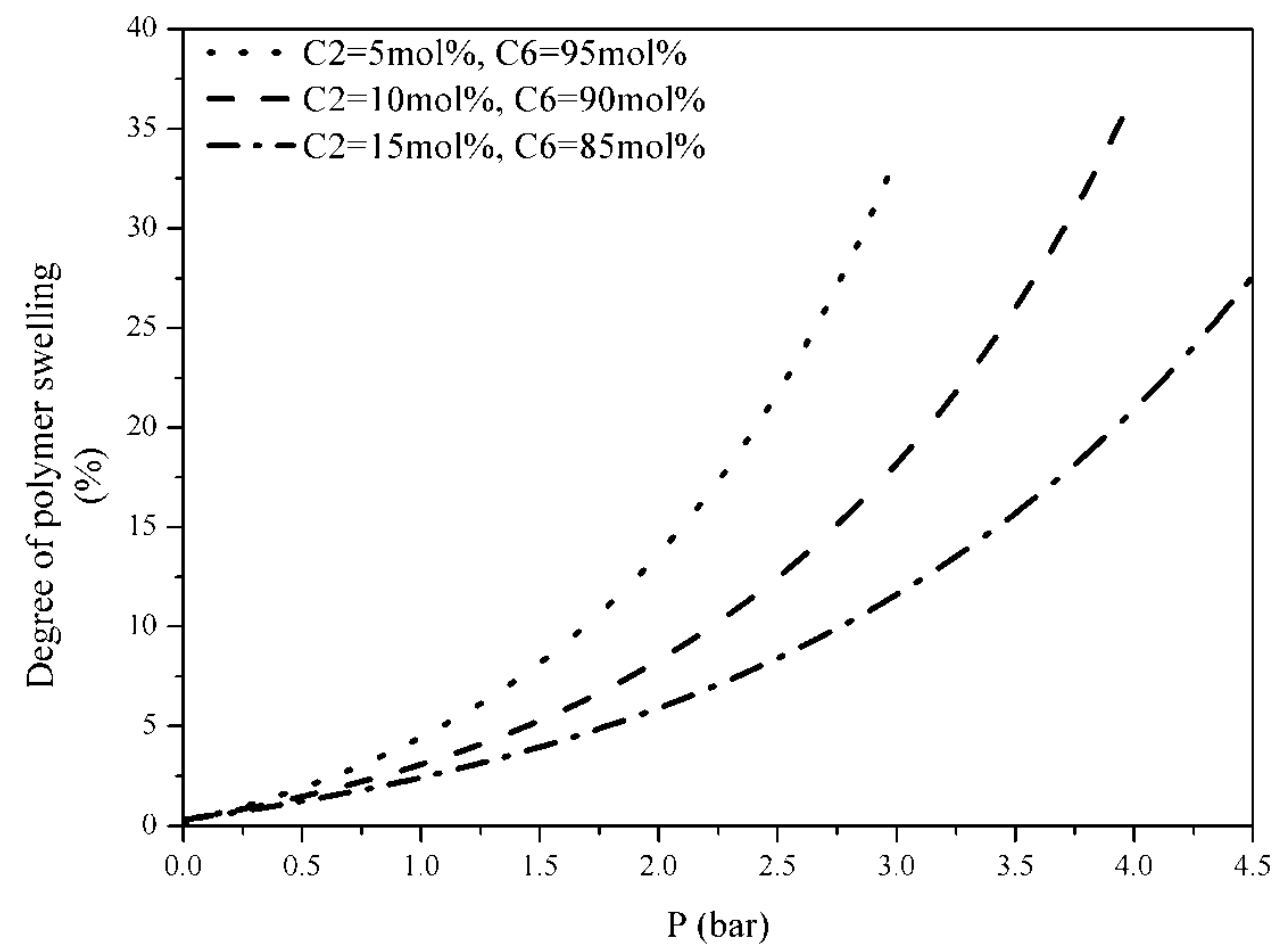

Figure 17. Degree of swelling of LLDPE during sorption of n-hexane/ethylene mixture at 90 ${ }^{\circ} \mathrm{C}$.

In the open literature as well as in the everyday industrial practice, the density of pure or unswollen polymer is often used for estimating the density of the solid-penetrants mixture inside the reactor at the operating conditions. ${ }^{[26]}$ Since the polymer particles are swollen due 
to the sorption of different penetrants, a more realistic approach is needed towards the calculation of the particle density to better design, plan and operate the process more efficiently.

The developed SL EoS thermodynamic model was employed for calculating the swollen polymer phase densities. Figure 18 shows the effect of penetrant/ethylene mixture (10 mol\% ethylene concentration) on the swollen polymer phase density at $70{ }^{\circ} \mathrm{C}$ and different pressures. As it can be seen, the swollen polymer phase densities for all systems exhibit a decrease with increasing pressure and they are substantially below the value that is commonly used for the pure LLDPE density (i.e., $915 \mathrm{Kg} / \mathrm{m}^{3}$ ). It is apparent that the higher the carbon number of alkane penetrant, the higher the degree of polymer swelling at a given temperature and pressure. It should also be highlighted that the swollen polymer phase density has a considerable dependence on the type of penetrant used, the composition and the molecular species of the multi-component system as well as the operating conditions.

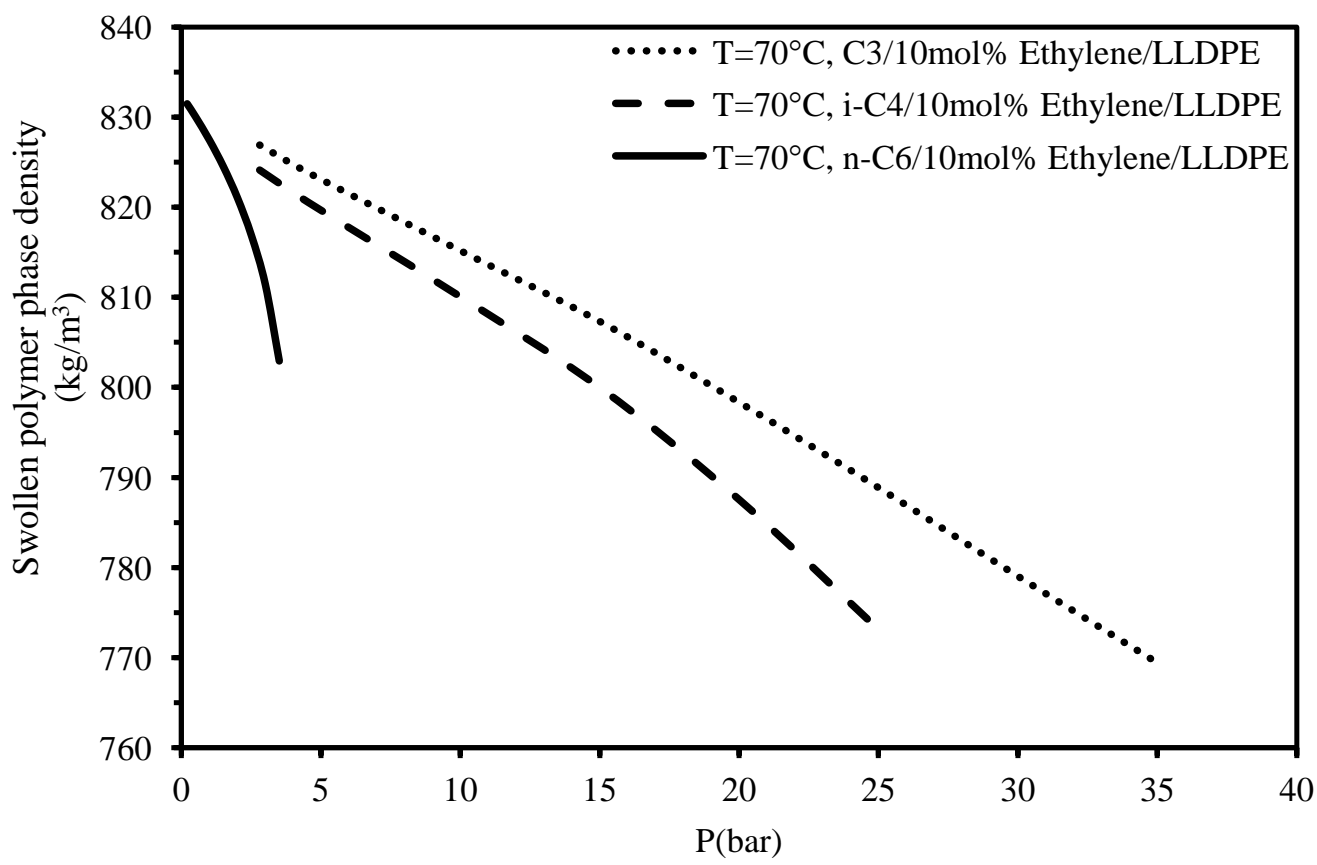

Figure 18. Swollen polymer phase density for various multi-component mixtures having feed composition of $90 \mathrm{~mol} \%$ penetrant and $10 \mathrm{~mol} \%$ ethylene at $70^{\circ} \mathrm{C}$. Binary interaction parameters (i.e., $k_{13}$ and $k_{23}$ ) were the same with those mentioned in Figures 8-12. 


\section{Particle Size Distribution in Olefin Polymerization Reactors}

Particle size distribution (PSD) is a key morphological property in catalytic olefin polymerization processes since it determines to a large extent the mixing phenomena in the polymerization reactors. It is also considered as one of the most important variables that affect both the reactor operability and the end-use properties of the final product.

To calculate the dynamic evolution of PSD in a polymerization reactor, a population balance model needs to be solved taking into account the growth rate of the polymer particles. Let us assume that the operation of an LLDPE reactor can be approximated by a perfectly mixed, continuous flow reactor. Catalyst particles (fresh or pre-polymerized) are fed into the bubbling gas-solid fluidized bed reactor $(\mathrm{FBR})$ at a constant rate $F_{c}(\mathrm{Kg} / \mathrm{s})$, while the mass of the solids in the FBR can vary with time, $W(t)(\mathrm{Kg})$. At steady-state, the mass of solids in the FBR is kept constant by controlling the product withdrawal rate, $F_{p}(\mathrm{Kg} / \mathrm{s})$. Assuming that particle attrition and elutriation were negligible as well as particles are spherical and of constant density, the following dynamic particle population balance equation, accounting for both particle growth and particle agglomeration can be derived: ${ }^{[40,41]}$

$\frac{\partial n_{p}(D, t)}{d t}+\frac{\partial\left[G_{p}(D) n_{p}(D, t)\right\rfloor}{\partial D}=B(D, t)-D(D, t)+\frac{1}{W}\left[F_{c} n_{c}(D)-F_{p} n_{p}(D, t)\right]$

where $n_{p}(D, t)$ and $n_{c}(D)$, expressed in $(\# / \mathrm{kg} / \mathrm{m})$, denote the corresponding number density functions of particles in the reactor and in the feed stream. The term $n_{p}(D, t) d D$ denotes the 
number of particles in the size range $(D, D+d D)$ per mass of polymer. According to Kanellopoulos et al. ${ }^{[42]}$ the particle growth rate, $G_{p}(D)$, can be expressed in terms of the overall particle polymerization rate as follows:

$$
G_{p}(D)=2 R_{p} /\left(\rho_{p} \pi D^{2}\right)
$$

It has to be pointed out that out of simplification, the overall particle polymerization rate, $R_{p}$, was assumed to be constant and to attain the same value for each discrete class of particles (see Table 3). One can easily show that at steady-state, the polymer mass withdrawal rate will be given by the following equation: ${ }^{[40]}$

$$
F_{p}=F_{c}+W \int_{D_{\min }}^{D_{\max }} G_{p}(D) n_{p}(D, t) d\left(\frac{\rho_{p} \pi D^{3}}{6}\right)
$$

Note that the second term on the right-hand side of the equation 7 above accounts for the total polymer production rate in the reactor. From that equation, one can calculate the product withdrawal rate, $F_{p}$, provided that the polymer weight, $W$, the particle growth rate, $G_{p}(D)$ , and the number density function, $n_{p}(D, t)$, are known. Alternatively, the calculation of the polymer weight, $W$, for given values of $F_{p}, F_{c}$ and $n_{p}(D, t)$ can be made. In addition, one can define in terms of $n_{p}(D, t)$, the probability density function $P_{p}(D, t) d D$, which represents the mass fraction of particles in the size range $(D, D+d D)$ :

$$
P_{p}(D, t) d D=\frac{\rho_{p} \pi D^{3}}{6} n_{p}(D, t) d D
$$


As a result, $P_{p}(D, t)$ will satisfy the following normalization condition:

$$
\int_{D_{\min }}^{\infty} P_{p}(D, t) d D=1
$$

The dynamic population balance equation described above (equation 5) was solved numerically using an accurate and efficient discretization method. ${ }^{[43]}$ It should be pointed out that the agglomeration and breakage terms (i.e., $B(D, t)$ and $D(D, t)$ terms in equation 5 were considered to be negligible.

The population balance model described above was further employed to simulate the effect of polymer phase swelling (i.e., differences in polymer phase density) on the final (i.e., steady state) particle size distribution of two different Ziegler-Natta catalysts (see Table 3). The reactor operating conditions, the materials feed rates as well as the catalyst characteristics are reported in Table 3.

Table 3. Nominal operating conditions of the LLDPE reactor.

\begin{tabular}{lc}
\hline Reactor operating conditions & Values \\
\hline Reactor volume, $\mathrm{V}_{\mathrm{R}}\left(\mathrm{m}^{3}\right)$ & 250 \\
Pressure, $\mathrm{P}_{\mathrm{R}}(\mathrm{bar})$ & 20 \\
Temperature $\left({ }^{\circ} \mathrm{C}\right)$ & 85 \\
Solids concentration, $\mathrm{S}_{\mathrm{s}}(\% \mathrm{wt})$ & 40 \\
Ethylene concentration, $\mathrm{C}_{\text {eth }}(\mathrm{mol} / \mathrm{l})$ & 0.25 \\
1-Butene concentration, $\mathrm{C}_{\text {but }}(\mathrm{mol} / \mathrm{l})$ & 0.10 \\
Propane concentration, $\mathrm{C}_{\text {prop }}(\mathrm{mol} / \mathrm{l})$ & 0.33 \\
Ethylene conversion $(\%)$ & 99.5 \\
Particle polymerization rate, $\mathrm{R}_{\mathrm{p}}(\mathrm{kg} / \mathrm{s})$ & 2.5 \\
Catalyst feed rate, $\mathrm{F}_{\mathrm{c}}(\mathrm{kg} / \mathrm{h})$ & 2 \\
Catalyst mean size, $\mathrm{d}_{\mathrm{c}}(\mu \mathrm{m})$ & 25 and 35 \\
Catalyst span $\left(\left(\mathrm{d}_{90}-\mathrm{d}_{10}\right) / \mathrm{d}_{50}\right)$ & 1.2 \\
Polymer density $(\mathrm{no} \quad \mathrm{swelling})$, & $\rho_{\mathrm{p}}$ \\
$\left(\mathrm{kg} / \mathrm{m}^{3}\right)$ & 915 \\
Mean residence time, $\tau(\mathrm{h})$ & \\
\hline
\end{tabular}


Figures 19 and 20 illustrate the PSDs of the polymer particles for two catalyst systems having the same relative standard deviation value of their PSD (i.e., span equals to 1.2) but different mean size (i.e., $25 \mu \mathrm{m}$ and $35 \mu \mathrm{m}$, respectively). Solid lines represent the PSDs in the case of constant polymer density (i.e., $915 \mathrm{~kg} / \mathrm{m}^{3}$ ), while dash lines represent the corresponding PSDs when polymer phase swelling was taken into account (i.e., calculated via the Sanchez-Lacombe Eos) resulting in lower polymer phase density values (i.e., $<850$ $\left.\mathrm{kg} / \mathrm{m}^{3}\right)$. In the same figures the initial catalyst size distributions as well as the final polymer size distributions are also depicted. According to the results of Figures 19 and 20, polymer swelling has an important effect on the polymer PSDs. As it can be seen the mean particle size of the particles considering the swelling effect is $\sim 15 \%$ larger compared to the corresponding mean size of the polymer particles for which a constant polymer density value was assumed (no swelling effect).

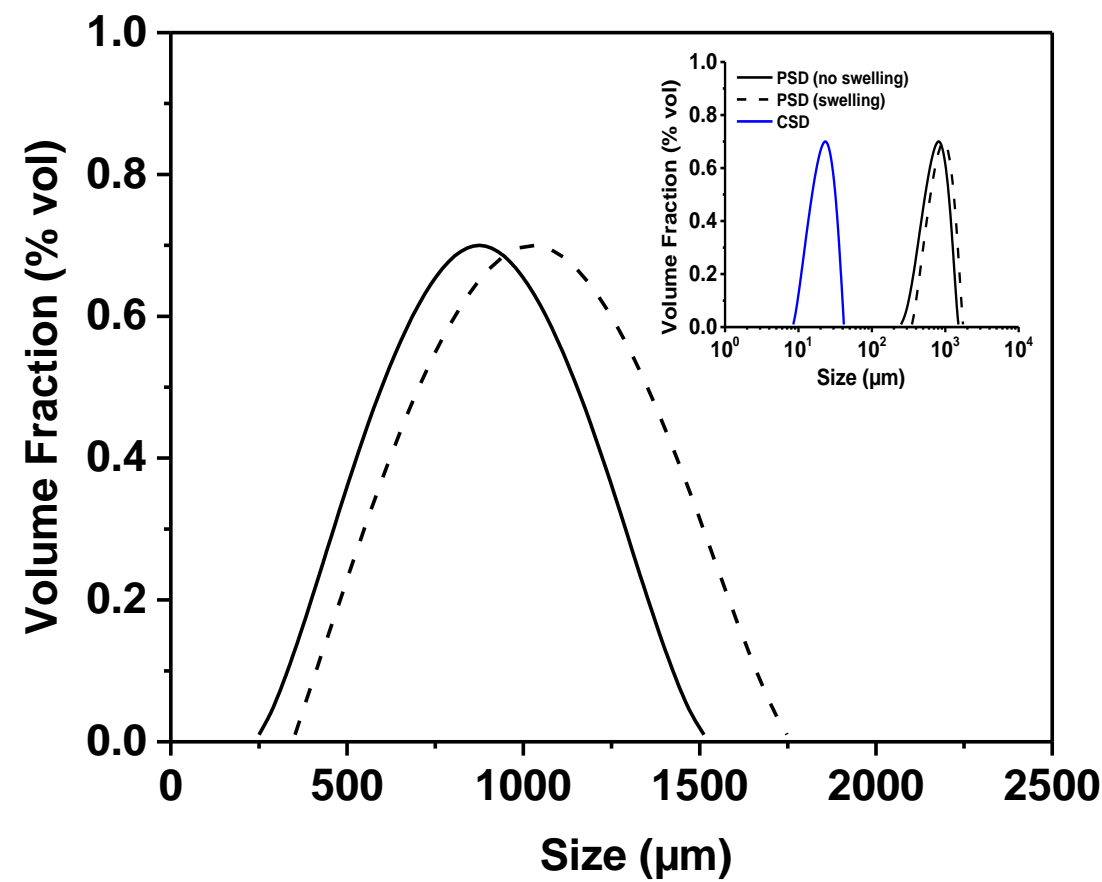

Figure 19. Effect of polymer phase swelling on PSD produced by a mean catalyst size of 25 $\mu \mathrm{m}$ and span=1.2. CSD refers to catalyst size distribution. 


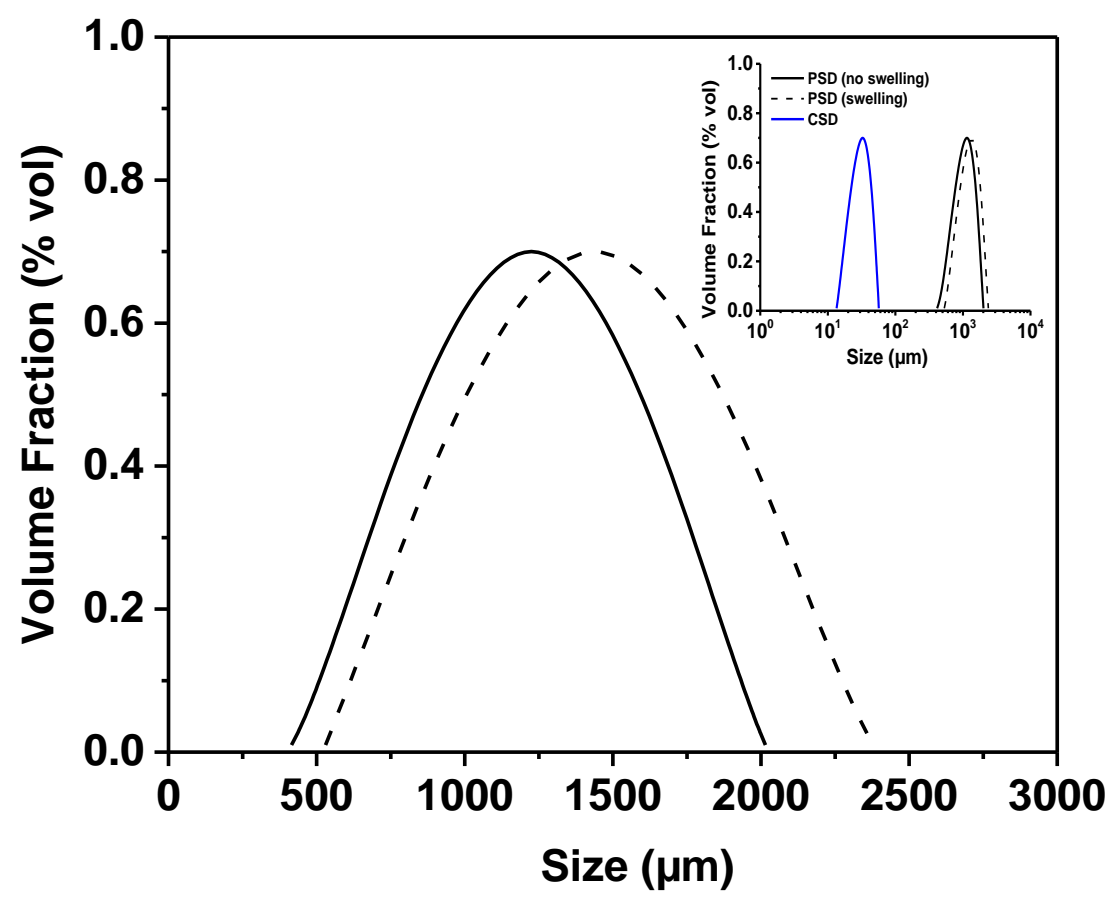

Figure 20. Effect of polymer phase swelling on PSD produced by a mean catalyst size of 35 $\mu \mathrm{m}$ and $\mathrm{span}=1.2$. CSD refers to catalyst size distribution.

It should be also pointed out that PSD developments in gas phase reactor (GPR) dramatically affect the selected fluidization conditions and the hydrodynamic behavior of the gas-solids mixture. Therefore, precise calculation of polymer PSD in FBRs can substantially contribute in achieving stabilized reactor operation.

\section{Conclusion}

The type of the penetrants used in a gas phase olefin polymerization processes has a significant effect on the reactor performance and operability. In the present study, the Sanchez-Lacombe Equation of State (SL EoS) was employed to investigate the effect of different penetrants used in industrial polyolefin production technologies on polymer phase density and degree of polymer swelling. It was demonstrated that higher alkanes like nhexane exhibits very high solubility in the polymer phase which can cause polymer softening 
and, consequently, can lead to reactor fouling. On the other hand, propane causes the lowest polymer swelling among the studied penetrants.

It was also shown that the solubility of all the studied ethylene/penetrant mixtures is lower than the solubility of pure penetrant and higher than that of pure ethylene in LLDPE. However, by increasing the ethylene concentration in the feed the overall mixture solubility decreases and tends to move towards the corresponding binary ethylene/LLDPE system at the studied operating conditions. A similar trend was observed for the polymer phase swelling caused by the penetrant/ethylene mass uptake over a wide range of temperatures and pressures.

Finally, the effect of polymer swelling on the particle size distribution developments in an industrial scale FBR was assessed. It was found that the PSD of the swollen growing polymer particles inside the reactor can be up to $15 \%$ different compared to the calculated one where polymer swelling due to penetrants sorption in the polymer phase was assumed to be negligible.

\section{Acknowledgement}

The authors would like to acknowledge Borealis Polymer Oy for supporting this work.

\section{References}

[1] V.Kanellopoulos and C. Kiparissides, 'Industrial Multi-modal Processes' in Multimodal polymers with Supported Catalysts, Springer Nature Switzerland AG, 2019, pp 155-203

[2] J. B. P. Soares, T. F. L. McKenna, Polyolefin Reaction Engineering, Wiley-VCH, Mannheim, Germany 2012.

[3] T. Xie, K.B. McAuley, J.C.C. Hsu, D.W. Bacon, Ind. Eng. Chem. Res., 1994, 33, 449

[4] M.F. Atan, M.A. Hussain, M.R. Abbasi, M.J.H. Khan, M.F.A. Patah, Processes, 2019, 7, 67, doi:10.3390/pr7020067

[5] A. Kiashemshaki, N. Mostoufi, R. Sotudeh-Gharebagh, Chem. Eng. Sci. 2006, 61, 3997

[6] G. Dompazis, V. Kanellopoulos, V. Touloupides, C. Kiparissides, Chem. Eng. Sci., 2008, 63, 4735 
[7] T.F.L. McKenna, Condensed Mode Cooling of Ethylene Polymerisation in Fluidised Bed Reactors, Macromol. React. Engng., 2019, 13, 1800026 doi: 10.1002/mren.201800026

[8] H. Pan, X.F. Liang, L.T. Zhu, Z.H. Luo, Adv. Powder Tech., 2016, 27, 1494

[9] H. Pan, X.F. Liang, L.T. Zhu, Z.H. Luo, Ind. Eng. Chem. Res., 2017, 56, 10199

[10] A. Mirazei, A. Kiashemshaki, M. Emani, Macromol. Symp. 2007, 259, 135

[11] A. Yiagopoulos, H. Yiannoulakis, V. Dimos, C. Kiparissides, Chem. Eng. Sci., 2001, 56,3979

[12] V. Touloupides, V. Kanellopoulos, P. Pladis, C. Kiparissides, D. Mignon, P. VanGrambezen, Chem. Eng. Sci., 2010, 65, 3208

[13] K. Chen, Z. Tian, N. Luo, B. Liu, Ind. Eng. Chem. Res,. 2014, 53, 19905

[14] A. Yiagolpoulos, H. Yiannoulakis, J. Morris, C. Kiparissides, Comp. Aided. Chem. Eng., 2001, 9, 327

[15] B. J. Banazsak, D. Lo, T. Widya, W. H. Ray, J. J. de Pablo, A. Novak, J. Kosek, Macromolecules 2004, 37, 9139

[16] A. Novak, M. Bobak, J. Kosek, B.J. Banaszak, D. Lo, T. Widya, W.H. Ray, J.J. e Pablo, J. Appl. Polym. Sci., 2006, 100, 1124

[17] Andrade, F. N., T.F.L. McKenna, Macromol. Chem. Phys. 2017, 218, 1700248. https://doi.org/10.1002/macp.201700248

[18] A. Alizadeh, F. Sharif, M. Ebrahimi, T.F.L. McKenna, Ind. Eng. Chem. Res., 2018, 57, 6097

[19] R. Alves, M.A. Bashir, T.F.L. McKenna, Ind. Eng. Chem. Res., 2017, 56, 13582

[20] H. Orbey, C. P. Bokis and C. C. Chen, Ind. Eng. Chem. Res., 1998, 37, 4481-4491.

[21] I. C. Sanchez, R. H. Lacombe, Macromolecules, 1978, 11, 1145-1156.

[22] A. S. Reginato, J. J. Zacca and A. R. Secchi , AIChE J., 2003, 49, 2642-2654.

[23] G. Dompazis, V. Kanellopoulos, V. Touloupidis, C. Kiparissides, Chem. Eng. Sci., 2008, 63, 4737

[24] P. Sarkar, S. K. Gupta, Polym Eng Sci, 1992, 32, 732-742.

[25] J. J. Zacca, W. H. Ray, Chemical Engineering Science, 1993, 48, 3743-3765.

[26] A. G. Mattos Neto, M. F. Freitas, M. Nele and J. C. Pinto , Ind. Eng. Chem. Res., 2004, 44, 2697-2715

[27] I. C. Sanchez, R. H. Lacombe , J. Phys. Chem., 1976, 80, 2352-2362.

[28] E. Neau , Fluid Phase Equilibria, 2002, 203, 133-140.

[29] M. A. Bashir, M. Al-haj Ali, V. Kanellopoulos and J. Seppälä , Fluid Phase Equilibria, 2013, 358, 83-90.

[30] M. A. Bashir, M. Al-haj Ali, V. Kanellopoulos, J. Seppala, E. Kokko and S. Vijay, Macromolecular Reaction Engineering, 2013, 7, 193-204

[31] B. Bonavoglia, G. Storti and M. Morbidelli , Ind. Eng. Chem. Res., 2005, 45, 1183 1200

[32] M. G. De Angelis, T. C. Merkel, V. I. Bondar, B. D. Freeman, F. Doghieri and G. C. Sarti , J. Polym. Sci. B Polym. Phys., 1999, 37, 3011-3026.

[33] Yahya A.I.Banat Fines generation in gas-phase ethylene polymerization. Doctoral thesis University of Twente, The Netherlands, 2006

[34] V. Kanellopoulos, D. Mouratides, P. Pladis and C. Kiparissides, Ind. Eng. Chem. Res., 2006, 45, 5870-5878.

[35] J. A. Meyer, R. F. Blanks , J. Appl. Polym. Sci., 1983, 28, 725-741.

[36] J. Chmelar, P. Matuska, T. Gregor, M. Bobak, F. Fantinel and J. Kosek, Chemical Engineering Journal, 2013, 228, 907-916 
[37] W. M. R. Parrish , J. Appl. Polym. Sci., 1981, 26, 2279-2291.

[38] W. Yao, X. Hu and Y. Yang, J. Appl. Polym. Sci., 2007, 103, 1737-1744.

[39] M.A. Bashir, V. Monteil, M. Al-Haj Ali, V. Kannelopoulos, T.F.L. McKenna, Macromol. Chem. Phys. 2015, 216, 2129-2140

[40] G. Dompazis, V. Kanellopoulos, C. Kiparissides, Macromolecular Materials and Engineering, 2005, 290, 525-536

[41] G. Dompazis, V. Kanellopoulos, V. Touloupides, C. Kiparissides, Chemical Engineering Science, 2008, 63, 4735-4753.

[42] V. Kanellopoulos, G. Dompazis, B. Gustafsson, C. Kiparissides, Industrial \& Engineering Chemistry Research, 2004, 43, 5166-5180.

[43] A.H. Alexopoulos, A.I Roussos, C. Kiparissides, Chemical Engineering Science, 2004, 24, 5751-5769 